ARTICLE

httpst//doi.org/10.1038/s41467-020-16975-2

\title{
Structural mechanism underlying primary and secondary coupling between GPCRs and the $\mathrm{Gi} / \mathrm{o}$ family
}

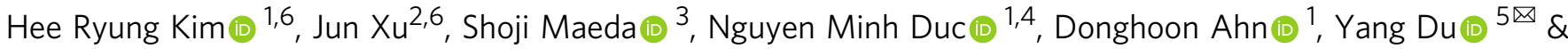
Ka Young Chung (i) ${ }^{1 凶}$

Heterotrimeric $G$ proteins are categorized into four main families based on their function and sequence, $\mathrm{Gs}, \mathrm{Gi} / \mathrm{o}, \mathrm{Gq} / 11$, and $\mathrm{G} 12 / 13$. One receptor can couple to more than one $\mathrm{G}$ protein subtype, and the coupling efficiency varies depending on the GPCR-G protein pair. However, the precise mechanism underlying different coupling efficiencies is unknown. Here, we study the structural mechanism underlying primary and secondary Gi/o coupling, using the muscarinic acetylcholine receptor type $2(\mathrm{M} 2 \mathrm{R})$ as the primary Gi/o-coupling receptor and the $\beta_{2}$-adrenergic receptor ( $\beta_{2} A R$, which primarily couples to $G$ s) as the secondary $\mathrm{Gi}$ /o-coupling receptor. Hydrogen/deuterium exchange mass spectrometry and mutagenesis studies reveal that the engagement of the distal C-terminus of Goi/o with the receptor differentiates primary and secondary $\mathrm{Gi} / \mathrm{o}$ couplings. This study suggests that the conserved hydrophobic residue within the intracellular loop 2 of the receptor (residue 34.51) is not critical for primary Gi/o-coupling; however, it might be important for secondary Gi/o-coupling.

\footnotetext{
${ }^{1}$ School of Pharmacy, Sungkyunkwan University, 2066 Seobu-ro, Jangan-gu, Suwon 16419, Republic of Korea. ${ }^{2}$ Beijing Advanced Innovation Center for Structural Biology, School of Medicine, Tsinghua University, Beijing 100084, China. ${ }^{3}$ Department of Molecular and Cellular Physiology, School of Medicine, Stanford University, 279 Campus Drive, Stanford, CA 94305, USA. ${ }^{4}$ Division of Precision Medicine, Research Institute, National Cancer Center, 323 Ilsanro, Ilsandong-gu, Goyang 10408, Republic of Korea. ${ }^{5}$ School of Life and Health Sciences, Kobilka Institute of Innovative Drug Discovery, Chinese University of Hong Kong, 2001 Longxiang Ave, Shenzhen, Guangdong 518172, China. ${ }^{6}$ These authors contributed equally: Hee Ryung Kim, Jun Xu.

凶email: yangdu@cuhk.edu.cn; kychung2@skku.edu
} 
G protein-coupled receptors (GPCRs) are the largest receptor superfamily that perceive extracellular signals, including light, smell, taste, hormones, and neurotransmitters ${ }^{1}$. Due to their critical functions in physiology and pathology, GPCRs are good therapeutic targets, and one third of approved medicines acts on GPCRs. Thus, it is important to understand the precise signaling mechanism of GPCRs for our fundamental knowledge on the cellular signaling and for the development of better GPCR-targeting therapeutics.

GPCRs propagate extracellular signals into cells by coupling with the heterotrimeric guanine-nucleotide-binding regulatory proteins ( $\mathrm{G}$ proteins) ${ }^{2}$. The heterotrimeric $\mathrm{G}$ proteins are formed by $\alpha, \beta$, and $\gamma$ subunits; in the basal state, $\mathrm{G} \alpha$ is occupied by guanosine diphosphate (GDP) and interacts with G $\beta \gamma$ subunits. An agonist-activated receptor interacts with a $G$ protein, which triggers the exchange of GDP for guanosine triphosphate (GTP), followed by dissociation of the Ga subunit from the receptor and $\mathrm{G} \beta \gamma$ subunits ${ }^{2,3}$. The GTP-bound Ga subunit or G $\beta \gamma$ subunits interact with and regulate downstream effector proteins. Based on their downstream function and sequence, the $G a$ subunits are grouped into four families, Gas (Gas and $\mathrm{Ga}_{\mathrm{olf}}$ ), Gai/o (Gail, Gai2, Gai3, Gao, Gat1, Gat2, Gat3, and Gaz), Gaq/11 (Gaq, Ga11, Ga14, and Ga16), and Ga12/13 (Ga12 and Ga13) ${ }^{1}$.

Approximately 800 GPCRs have been identified in humans. Previous studies have reported that many GPCRs exhibit promiscuous GPCR-G protein coupling; i.e., a single receptor can interact with more than one $G$ protein subtype ${ }^{4-6}$. One receptor often couples to more than one $\mathrm{Ga}$ isoform within the same family due to high sequence similarity ${ }^{5}$. For example, the serotonin 1 A receptor interacts with three Gi/o family proteins, Gi2, $\mathrm{Gi} 3$, and $\mathrm{Go}^{5}$. Moreover, several receptors can couple to different G protein families; the $\alpha_{2}$ - and $\beta_{2}$-adrenergic receptors $\left(\alpha_{2} A R\right.$ and $\beta_{2} \mathrm{AR}$ ) interact with $\mathrm{Gs}$ and $\mathrm{Gi} / \mathrm{o}^{7,8}$, the PAR1 receptor with $\mathrm{Gi} / \mathrm{o}$ and $\mathrm{G} 12 / 13^{9}$, and the melanin-concentrating hormone receptor 1 with $\mathrm{Gi} / \mathrm{o}$ and $\mathrm{Gq} / 11^{10}$.

The interaction efficiency and/or binding kinetics of one receptor to different $G$ proteins often differ. The most prominent coupling, which shows the highest coupling efficiency with fast kinetics, is referred to as 'primary coupling'. The minor coupling, which shows lower coupling efficiency and/or slower kinetics, is referred to as 'secondary coupling'11,12. The known primary and secondary GPCR-G protein pairs have been summarized in the IUPHAR/BPS Guide to Pharmacology ${ }^{11}$ and GPCRdb (gpcrdb. org) (Supplementary Fig. 1a).

Several biochemical/biophysical studies have revealed the conformational dynamics and high-resolution structures of $\mathrm{G}$ proteins in various states ${ }^{1,3}$. These structures of GPCR-G protein complexes reveal the interactions between GPCRs and nucleotide-free $\mathrm{G}$ proteins ${ }^{13-15}$. The X-ray crystal structure of the $\beta_{2}$ AR-Gs complex ${ }^{15}$ and the cryo-electron microscopy (cryo-EM) structure of the muscarinic acetylcholine receptor type 2-GoA (M2R-GoA) complex ${ }^{16}$ are shown in Supplementary Fig. 2. The major binding interface between a receptor and a $G$ protein for both structures is between the C-terminal part of a 5 of the $\mathrm{Ga}$ subunit and the cytosolic core of the receptor formed by transmembrane domains (Supplementary Fig. 2). The distal Cterminus of $\mathrm{Ga}$ (the so-called 'wavy hook') (Supplementary Fig. 2c, green dotted line $)^{17,18}$ forms an additional $\alpha$-helical-turn as an extension of $a 5$ when it interacts with a receptor (Supplementary Fig. 2c). Another interface is the intracellular loop 2 (ICL2) of the receptor interacting with the hydrophobic pocket of $\mathrm{G} \alpha$ formed by hydrophobic residues at the $\alpha \mathrm{N} / \beta 1$ hinge, $\beta 2 / \beta 3$ loop, and a5 (Supplementary Fig. 2a, blue dotted box). This interaction appears to be weaker for M2R-GoA structure compared with $\beta_{2}$ AR-Gs, which is discussed below.
Recently, using a combination of pulsed hydrogen/deuterium exchange mass spectrometry (HDX-MS), pulsed hydroxyl radical footprinting mass spectrometry (HRF-MS), and mutational studies, we proposed a model that delineates the sequential events during $\beta_{2}$ AR-Gs coupling, the primary GPCR-Gs pair ${ }^{19}$. In brief, the $\mathrm{C}$-terminal region of Gas initially associates with the $\beta_{2} \mathrm{AR}$ followed by interaction of ICL2 with the hydrophobic pocket within Gas, which is the key step for GDP release (see below). Stable helix formation of the Gas wavy hook occurs slowly after GDP release.

Although there has been a great progress in understanding the structural mechanism of GPCR-G protein coupling as described above, the structural mechanism of different coupling efficiencies observed from the primary and the secondary coupling has not been clearly elucidated. In the current study, we took advantage of HDX-MS and investigate the structural mechanism that differentiates primary and secondary GPCR-Gi/o coupling using the M2R and the $\beta_{2} A R$ as model GPCRs, and Gi3 and GoA as model $\mathrm{Gi} / \mathrm{o}$ proteins. The data suggest that the C-terminus of Gai/o differentiates primary and secondary Gi/o-coupling and that residue 34.51 of the receptor is not important for the primary $\mathrm{Gi}$ / o coupling.

\section{Results}

M2R- and $\beta_{2} A R$-induced GDP release from Gi/o proteins. The IUPHAR/BPS Guide to Pharmacology ${ }^{11}$ specifies that the M2R transduces signals primarily through Gi/o family and secondarily through Gs and Gq/11 families, and the $\beta_{2} A R$ transduces signals primarily through Gs family and secondarily through Gi/o family (Supplementary Fig. 1b). Especially, the coupling efficiencies of the $\beta_{2} \mathrm{AR}$ with $\mathrm{Gs}$ or $\mathrm{Gi} / \mathrm{o}$ families have been studied extensively both in vitro and in vivo ${ }^{20-22}$, and the coupling efficiencies of the M2R with Gs, Gi/o, and Gq/11 families have been studied in vivo 23,24 .

To confirm the different coupling efficiencies of the two different receptors (i.e., primary vs. secondary) for Gi/o proteins, we analyzed receptor-mediated GDP release using purified proteins in vitro. Herein, we used Gi3 and GoA as model Gi/o proteins (Fig. 1a) as the $\beta_{2} \mathrm{AR}-\mathrm{Gi} 3$ interaction has been wellcharacterized in a previous study ${ }^{21}$, and the high-resolution structure of M2R-GoA has been resolved by cryo-EM ${ }^{16}$. To achieve optimal $\beta_{2}$ AR-Gi/o coupling, we used micelles composed of negatively charged lipids (DDM with POPE at a ratio of 5:1) as the previous study had shown that the charge state of the lipid surrounding the $\beta_{2} \mathrm{AR}$ affects the efficiency of $\mathrm{Gi} / \mathrm{o}$ coupling ${ }^{21}$. As expected, the M2R coupled more efficiently to both $\mathrm{Gi} 3$ and GoA than the $\beta_{2} \mathrm{AR}$, as demonstrated by faster GDP release, with higher efficacy (Fig. 1b) confirming that M2R is primary Gi/ocoupled receptor and $\beta_{2} \mathrm{AR}$ as secondary Gi/o-coupled receptor. Notably, our previous study showed that the $\beta_{2} A R$ induced almost complete GDP release from Gs within $10 \mathrm{~s}^{19}$, confirming that the $\beta_{2} \mathrm{AR}$ primarily couples to Gs.

M2R- or $\beta_{2} A R$-induced HDX profile changes in GaoA. Previously, we analyzed the conformational differences between GDP-bound Gas and $\beta_{2}$ AR-bound nucleotide-free Gas using HDX-MS ${ }^{25}$; HDX levels near the nucleotide-binding pocket were higher in $\beta_{2}$ AR-bound nucleotide-free Gas than in GDP-bound Gas, which reflects GDP release and increased structural dynamics in this region (Supplementary Fig. 3). The C-terminal part of a5 of Gas displayed a lower HDX level in $\beta_{2}$ AR-bound nucleotide-free Gas than in the GDP-bound Gas (Supplementary Fig. 3) reflecting a stable helix formation and insertion into the receptor cytosolic core (described in Supplementary Fig. 2c). 
a

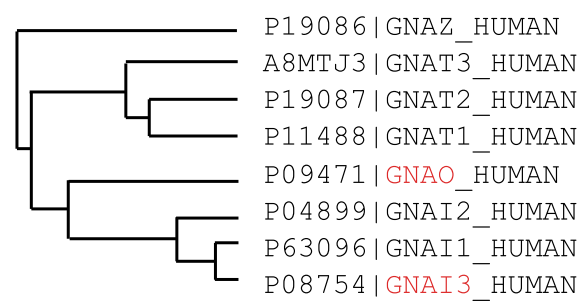

b

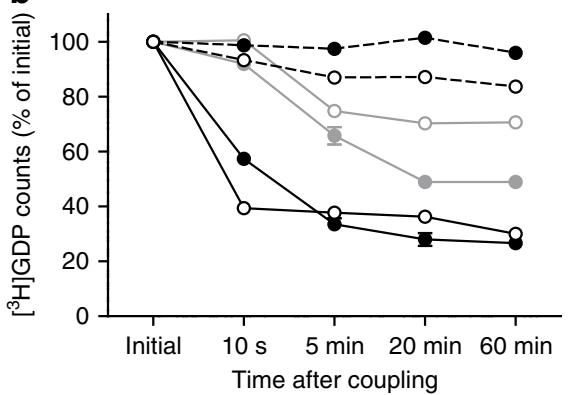

$*\left[\begin{array}{l}\bullet-\mathrm{M} 2 \mathrm{R}-\mathrm{Gi3} \\ -\beta_{2} \mathrm{AR}-\mathrm{Gi3}\end{array}\right.$

*[ $-0-$ M2R-GoA

$*\left[\begin{array}{l}-\mathrm{G} \cdot \mathrm{Gi} 3 \text { alone } \\ -\mathrm{O} \cdot \mathrm{GoA} \text { alone }\end{array}\right.$

]$*] *]$ *
C ${ }_{\mathrm{M} 2 \mathrm{R}}$

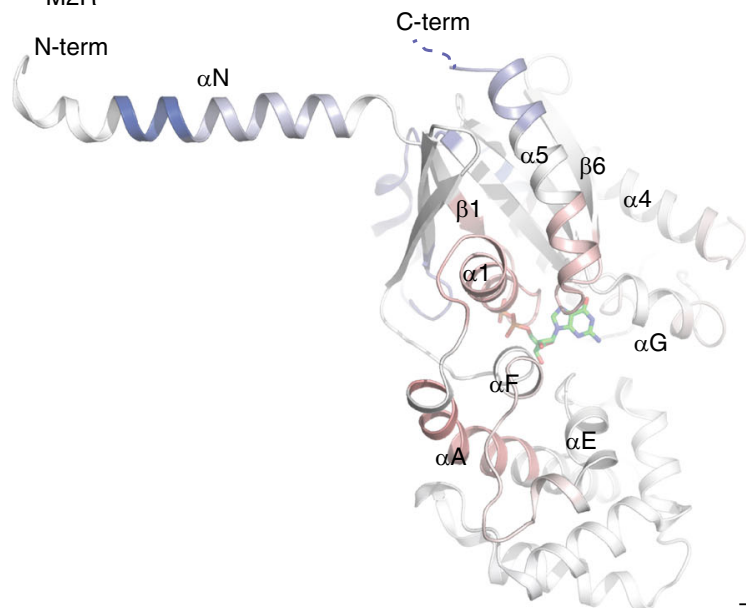

d

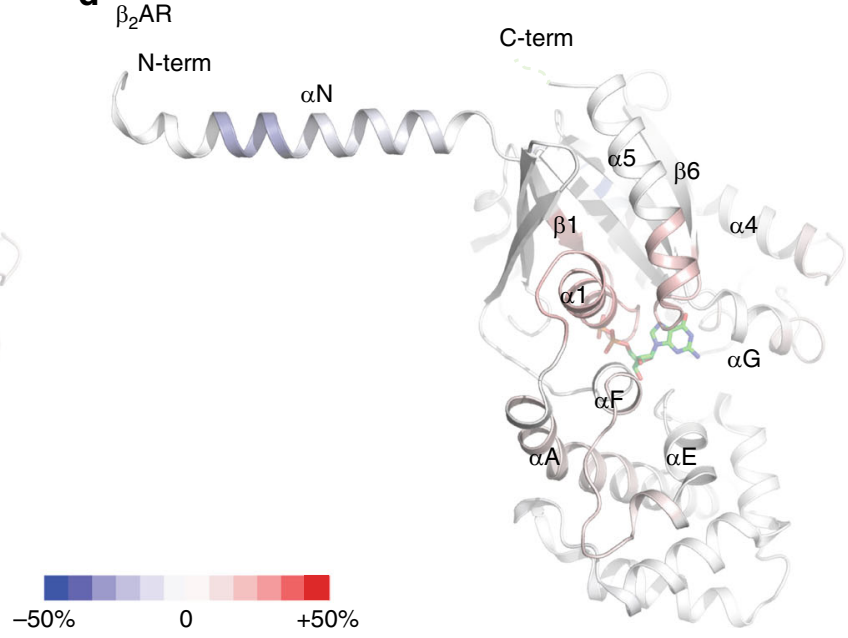

C-term

Fig. 1 GDP release and HDX-MS analysis of different GPCR-G protein pairs. a Phylogenic tree of Goi/o families. The phylogenic tree is generated based on the protein sequences provided by UNIPROT database (uniprot.org). The uniprot ID is indicated in front of the protein names. $\mathbf{b}$ GDP release profiles of GoA and Gi3, induced by the M2R or the $\beta_{2} A R$. * Indicates statistical differences between groups analyzed by one-way ANOVA test ( $\left.p<0.05\right)$. Error bars represent mean \pm S.E.M. of three independent experiments. Source data are provided as a Source data file. c, $\mathbf{d}$ HDX level changes of G $\alpha O A$ after $3 \mathrm{~h}$ of incubation with the M2R (c) or the $\beta_{2} A R$ (d). The changes in HDX are color-coded on the X-ray crystal structure of Goi1 (PDB 1GP2). The deuterium uptake plots are provided in Supplementary Fig. 4 a.

To understand the structural mechanism of different GDP release efficiencies between M2R-Gi/o and $\beta_{2} \mathrm{AR}-\mathrm{Gi} / \mathrm{o}$ pairs, here we analyzed HDX levels of GaoA in GDP-bound GoA heterotrimer alone and in GoA heterotrimer after M2R or $\beta_{2}$ AR co-incubation (Fig. 1c, d and Supplementary Fig. 4a). The co-incubation of GoA with the M2R or the $\beta_{2} \mathrm{AR}$ did not affect HDX profiles of G $\beta \gamma$ subunits (Supplementary data) implying that $G \beta \gamma$ subunits do not undergo significant conformational changes upon complex formation with the M2R or the $\beta_{2} A R$. When GoA was incubated with its primary coupling receptor M2R, we detected decreased HDX at the C-terminal part of a5 (Fig. 1c and Supplementary Fig. 4a, peptides 341-348 and 349353), which suggests decreased dynamics and/or exclusion from the buffer. We detected increased HDX near the nucleotide binding pocket (Fig. 1c and Supplementary Fig. 4a, peptides 37$52,268-275$, and 324-333), which suggests GDP release and/or increased dynamics. We also detected increased HDX between Ras-like and $\alpha$-helical domains (Fig. 1c and Supplementary Fig. 4a, peptides 53-61, 276-285, and 289-298) and a few peptides from the $\alpha$-helical domain (AHD) (Fig. 1c and Supplementary Fig. 4b, peptides 65-77 and 161-173), which could be attributed to domain opening and dynamic movement of $\mathrm{AHD}^{26}$. These results are consistent with those of the previous HDX-MS study that analyzed $\beta_{2}$ AR-Gs complex (Supplementary Fig. 3a) ${ }^{25}$. We detected decreased HDX at $\alpha \mathrm{N}$ (Fig. 1c and Supplementary Fig. 4a, peptides 14-18 and 19-29), which was not detected in $\beta_{2}$ AR-Gs complex due to lack of identified peptides in this region; the decreased $\mathrm{HDX}$ at aN may reflect the interaction of this region with the M2R (Supplementary Fig. 2b) and/or the blockage of this region from the buffer by micelles surrounding the receptor.

When GoA was incubated with the $\beta_{2} \mathrm{AR}$, a secondary coupling receptor, the HDX profile changes were similar in most regions except the C-terminal part of a5 (Fig. 1c, d). For instance, we detected increased HDX near the nucleotide-binding pocket and AHD, and decreased HDX at $\alpha \mathrm{N}$, although to a lesser extent than the M2R-GoA pair (Fig. 1d and Supplementary Fig. 4a). However, surprisingly, the C-terminal part of GaoA did not show HDX profile changes (Fig. 1d and Supplementary Fig. 4a, peptides 341-342 and 349-353), which implies that the Cterminal part of GaoA may not form the stable helix upon $\beta_{2} \mathrm{AR}$ GoA coupling and/or may not be deeply inserted into the receptor core.

Time-resolved HDX during M2R- and $\beta_{2} \mathrm{AR}-\mathrm{Gi} / \mathrm{o}$ coupling. The HDX profile changes shown in Fig. 1 are comparisons between before and after $3 \mathrm{~h}$ of co-incubation of GoA with the receptors. Three hours of co-incubation of the receptor and GoA is sufficient for completion of GDP release and formation of the final receptor-GoA complex ${ }^{16,21}$. Therefore, the data in Fig. 1 do not reflect transient conformational changes during coupling.

Recently, we performed HDX-MS in a pulsed manner to gain insight into time-resolved conformational changes during primary 
GPCR-Gs coupling using $\beta_{2}$ AR-Gs pair as model system ${ }^{19}$. In this previous study, the $\beta_{2} \mathrm{AR}$ and $\mathrm{Gs}$ were sampled before coincubation, and after $10 \mathrm{~s}, 5 \mathrm{~min}, 20 \mathrm{~min}, 60 \mathrm{~min}, 90 \mathrm{~min}, 110 \mathrm{~min}$, $150 \mathrm{~min}$, and $180 \mathrm{~min}$ of co-incubation. The sampled proteins were then pulsed with deuterated buffer for 10 or $100 \mathrm{~s}^{19}$. This approach provides the HDX profiles of the indicated time points, which reflect the conformational states of the $\beta_{2} A R$ and Gs at the sampled time points (Supplementary Fig. 5a). Pulsed HDX-MS analysis of $\beta_{2} \mathrm{AR}-\mathrm{Gs}$ revealed HDX profile change at ICL2 of the $\beta_{2} \mathrm{AR}$ within $10 \mathrm{~s}$ of co-incubation (Supplementary Fig. 5a, peptides 133-144) whereas the HDX profile change continued until $110 \mathrm{~min}$ at the $\mathrm{N}$-terminal part of ICL3 (Supplementary Fig. 5a, peptide 223-240), which suggests that ICL2 undergoes conformational changes faster than ICL3 upon coupling to Gs. Analysis of Gas detected rapid HDX profile changes at the nucleotide-binding pocket (Supplementary Fig. 5a, peptides 49-59 and 367-371) and slow and prolonged HDX profile changes at the C-terminus of a5 (Supplementary Fig. 5a, peptide $382-390)^{19}$. We confirmed that GDP release occurs within $10 \mathrm{~s}$ of co-incubation with the $\beta_{2} \mathrm{AR}$ indicating that the rapid HDX profile changes at the nucleotide-binding pocket was mainly due to GDP release ${ }^{19}$. Interestingly, the prolonged HDX profile changes at the $\mathrm{C}$ terminus of a5 suggested that this region undergoes prolonged conformational changes even after GDP release ${ }^{19}$.

In the current study, we adopted the same strategy to investigate whether the C-terminal part of Gai/o does ever form a stable helix and/or is inserted into the receptor cytosolic core, during the time-course of $\beta_{2}$ AR-Gi/o coupling (Fig. 2 and Supplementary Fig. 5b). We used $10 \mathrm{~s}$ deuterium pulse for M2RGi/o coupling and 10 and $100 \mathrm{~s}$ deuterium pulses for $\beta_{2} \mathrm{AR}-\mathrm{Gi} / \mathrm{o}$ coupling because $10 \mathrm{~s}$ deuterium pulse was not sufficient to observe HDX differences between Gi/o alone and Gi/o coincubated with the $\beta_{2} \mathrm{AR}$, for a few peptides (for example, peptides 37-52, 53-61, 268-275, and 324-333 in Supplementary Fig. 4a). Again, we did not detect any HDX profile changes of $\mathrm{G} \beta \gamma$ subunits during the co-incubation time course (Supplementary data).

When GoA or Gi3 was co-incubated with the M2R, the HDX profile change at $\alpha \mathrm{N}$ was initiated within $10 \mathrm{~s}$ and completed within $10 \mathrm{~s}$ to $5 \mathrm{~min}$ (peptides 14-18 and 19-29 for GaoA in Fig. 2 and peptides 6-18 and 19-33 for Gai3 in Supplementary Fig. 5b). The HDX profile changes of $\alpha \mathrm{N}$ showed similar results when Gi3 or GoA was incubated with the $\beta_{2} \mathrm{AR}$ (Fig. 2 and Supplementary Fig. 5b). However, the previous study with the $\beta_{2} A R$ and Gs reported that HDX profile at $\alpha \mathrm{N}$ of Gas increased within $10 \mathrm{~s}$ of incubation with the $\beta_{2} \mathrm{AR}$ (Supplementary Fig. 5a) suggesting that the conformational changes at $\alpha \mathrm{N}$ may differ between GPCR-Gs and GPCR-Gi/o coupling.

The HDX profile change near the nucleotide-binding pocket was initiated within $10 \mathrm{~s}$ and completed within 5-20 min in M2RGi3/GoA pairs (peptides 37-52 and 324-333 for GaoA in Fig. 2 and peptides 37-52 and 324-334 for Gai3 in Supplementary Fig. 5b). Interestingly, GDP release was completed within $10 \mathrm{~s}$ to 5 min for M2R-Gi/o coupling (Fig. 1b), which was faster than the changes in HDX-MS profile near the nucleotide-binding pocket. This may reflect further conformational changes after GDP release; the initial HDX profile changes within $10 \mathrm{~s}$ to $5 \mathrm{~min}$ were due to GDP release, while the later HDX profile changes observed at $20 \mathrm{~min}$ were due to additional conformational changes after GDP release. However, we cannot exclude the possibility that these discrepancies between GDP release and HDX-MS profile change kinetics could also be due to different experimental conditions between the two assay systems such as protein concentration (see the Methods for details).

When Gi3 or GoA was incubated with the $\beta_{2} A R$, the HDX profile changes near the nucleotide-binding pocket were initiated within $10 \mathrm{~s}$ and completed within $10 \mathrm{~s}$ to $5 \mathrm{~min}$, which was faster than M2R-Gi3/GoA pairs (Fig. 2 and Supplementary Fig. 5b). The GDP release was initiated within $5 \mathrm{~min}$ and completed within 20 min of co-incubation of the $\beta_{2} \mathrm{AR}$ and Gi3/GoA (Fig. 1b), and the discrepancies between GDP release and HDX-MS profile change kinetics could be due to different experimental conditions between the two assay systems; the coupling may be slower in the GDP release assay probably due to lower protein concentrations. Overall, it is tempting to propose that the nucleotide-binding pocket undergoes further conformational changes after GDP release in M2R-Gi3/GoA coupling whereas the conformational changes near the nucleotide-binding pocket in $\beta_{2} \mathrm{AR}-\mathrm{Gi} / \mathrm{GoA}$ pairs are smaller and quicker probably due to the lack of further conformational changes after GDP release.

The HDX profile of the C-terminal part of GaoA continued to decrease until 150-180 min during M2R-GoA coupling (Fig. 2, peptides 342-348 and 349-353), which is similar to what we observed with $\beta_{2}$ AR-Gs coupling ${ }^{19}$ (Supplementary Fig. 5a, peptides 382-390). On the other hands, during M2R-Gi3 coupling, the HDX profile change at the C-terminal part of Gai3 was initiated within $10 \mathrm{~s}$ and continued to decrease until 20 min (Supplementary Fig. 5b, peptides 342-348 and 349-353). The molecular mechanism underlying the different HDX profile change kinetics at the C-terminal part of GaoA and Gai3 needs further investigation. Interestingly, when incubated with the $\beta_{2} \mathrm{AR}$, the C-terminal part of GaoA or Gai3 never showed decreased HDX at any time point during coupling (Fig. 2 and Supplementary Fig. 5b).

In summary, the M2R-induced HDX profile changes in GaoA or Gai3 were similar to what we observed for the $\beta_{2} A R$-induced HDX profile changes in Gas except at the aN. However, $\beta_{2}$ ARGi/o complex showed no HDX-MS profile change at the Cterminal part of Gai/o, which implied that this region of Gai/o does not form stable helices during $\beta_{2} \mathrm{AR}-\mathrm{Gi} / \mathrm{o}$ coupling and/or may not be deeply inserted into the cytoplasmic core of the receptor.

The role of the wavy hook for Gi/o coupling. As the C-terminal part of Gai/o displayed the most differences in HDX-MS profiles between M2R-Gi/o and $\beta_{2} \mathrm{AR}-\mathrm{Gi} / \mathrm{o}$ coupling, we hypothesized that the C-terminal part of Gai/o differentiates between primary and secondary GPCR-Gi/o coupling.

The C-terminal part of Ga that we analyzed with HDX-MS can be divided into two parts; one is the distal C-terminus (Fig. 3a, green-colored residues, 'wavy hook'), and the other is the Cterminal helical region of a5 (Fig. 3a, black residues). In our previous study with the $\beta_{2} \mathrm{AR}$ and Gs, we observed that the Cterminal part of $\mathrm{Ga}$ is the initial site that undergoes a change in hydroxyl radical foot printing upon interaction with the $\beta_{2} \mathrm{AR}^{19}$. Moreover, the $\beta_{2} \mathrm{AR}$ failed to induce GDP release from the wavy hook-truncated Gas, which suggested that the wavy hook is the critical initial binding site during $\beta_{2} \mathrm{AR}-\mathrm{Gs}$ coupling ${ }^{19}$ (see below).

To test the role of the wavy hook in GPCR-Gi/o coupling, we also generated a Gai3 mutant construct in which the last five residues were truncated (hereafter denoted Gi3_A5). Unlike $\beta_{2} \mathrm{AR}-\mathrm{Gs}$ coupling, both the M2R and the $\beta_{2} \mathrm{AR}$ could induce GDP release from Gi3_ $\Delta 5$ (Fig. $3 \mathrm{~b}$ ). Interestingly, $\beta_{2} \mathrm{AR}$-induced GDP release profile did not change upon C-terminal truncation, while M2R-induced GDP release was decreased so that the extent of this GDP release became similar between $\beta_{2} \mathrm{AR}-\mathrm{Gi} 3, \beta_{2} \mathrm{AR}$ Gi3_ $\Delta 5$, and M2R-Gi3_ $\Delta 5$ (Fig. 3b). These data suggest that the wavy hook of Gai3 has a role in differentiating between primary and secondary coupling; it is likely that the engagement of the wavy hook of Gai3 with a receptor is necessary for primary 

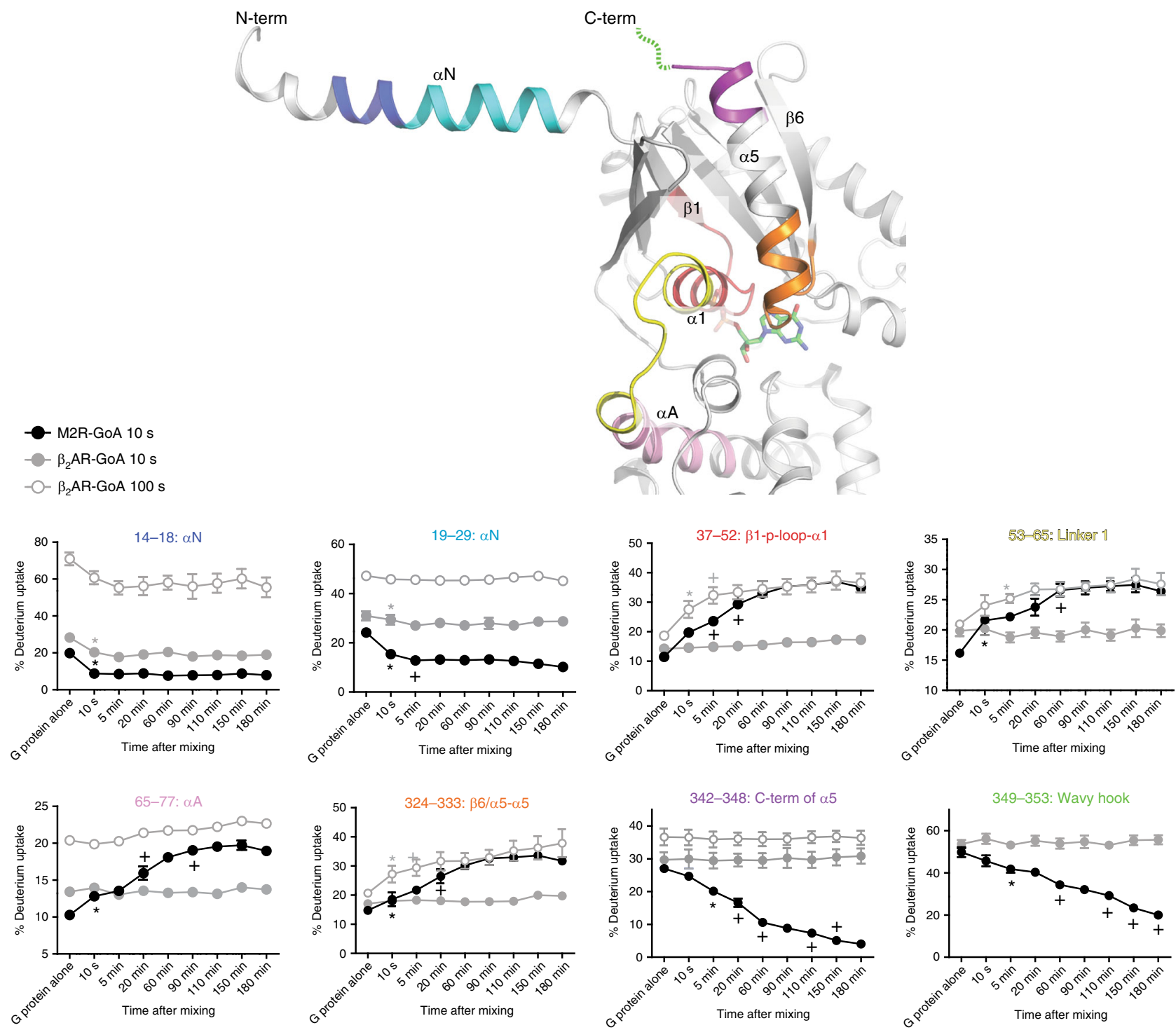

Fig. 2 Time-resolved HDX profiles of GooA during M2R-GoA and $\boldsymbol{\beta}_{\mathbf{2}} \mathbf{A R}-\mathbf{G o A}$ coupling. The selected analyzed peptides are color-coded on the X-ray crystal structure of Goi1 (PDB 1GP2) and on the titles of deuterium uptake graphs. Statistically significant changes during coupling were analyzed by repeated-measures ANOVA (rANOVA). To compare two different time points, a two-tailed paired Student's t-test was performed, and $p<0.05$ was considered as statistically significant. ${ }^{*}$ Indicates the first time point that showed a statistical difference compared with before co-incubation. + Indicates the first time point that showed a statistical difference from previously marked (either * or + ) time point. Error bars represent mean \pm S.E.M of three independent experiments. Please note that the data is plotted using a non-linear/non-logarithmic scale.

(i.e., strong) coupling, while failure in doing so (evident from HDX-MS studies of $\beta_{2} \mathrm{AR}-\mathrm{Gi} / \mathrm{o}$ coupling or from GDP release analysis of M2-Gi3_ $\Delta 5$ coupling) leads to secondary (i.e., weak) coupling.

The role of the wavy hook for GPCR-Gi/o coupling selectivity. As Gi3_ $\Delta 5$ could still couple with receptors (Fig. 3b), we hypothesized that truncation of the wavy hook of Gi3 results in loss of coupling selectivity and leads to promiscuous coupling with non-Gi/ o-coupling receptors. To test this hypothesis, we analyzed the GDP release activity of the M1R on WT Gi3 and Gi3_ $\Delta 5$. According to the IUPHAR/BPS Guide to Pharmacology and a previous report, the M1R primarily couples with Gq/1124 (Supplementary Fig. 1b), and we confirmed that the M1R does not couple with WT Gi3 (Fig. 3c). However, we clearly observed M1R-induced GDP release from Gi3_ $\Delta 5$, although the coupling efficiency was low (approximately $20 \%$ GDP release) (Fig. 3c). These data support our hypothesis that truncation of the distal C-terminus of $\mathrm{Gi} 3$ induces promiscuous coupling with non-Gi/o-coupling receptors.

The potential mechanism of promiscuous coupling of Gi3_ $\Delta 5$ with the M1R may be attributed to its higher intrinsic dynamics relative to WT Gi3. In other words, the wavy hook may assist in retaining Gi3 in the GDP-bound state. However, we did not detect any difference in basal GDP release between WT Gi3 and Gi3_s5 (Fig. 3c). To further investigate the basal GDP/GTP exchange tendency, we analyzed the uptake of BODIPYconjugated GTP $\gamma$ S (BODIPY-GTP $\gamma$ S) into WT Gai3 and Gai3_ $\Delta 5$. We used the a subunit of Gi3-without forming a heterotrimer with G $\beta \gamma$-to facilitate GDP/GTP turnover (Fig. 3d, e). The BODIPY fluorescence increases when BODIPY-GTP $\gamma \mathrm{S}$ is located within the nucleotide-binding pocket compared with when it is free in the buffer allowing the detection of GTP $\gamma \mathrm{S}$ binding by measuring the BODIPY fluorescence ${ }^{27,28}$. BODIPYGTP $\gamma S$ binding to WT Gai3 and Gai3_ $\Delta 5$ occurred with similar kinetics (Fig. 3d), although the maximal binding was slightly 
a
Gs ${ }^{H 5.15}$ IQFMHLRQYELL
Gi1 IIKNNLKDCGLF
Gi2 IIKNNLKDCGLF
Gi3 IIKNNLKECGLY
GOA IIANNLRGCGLY

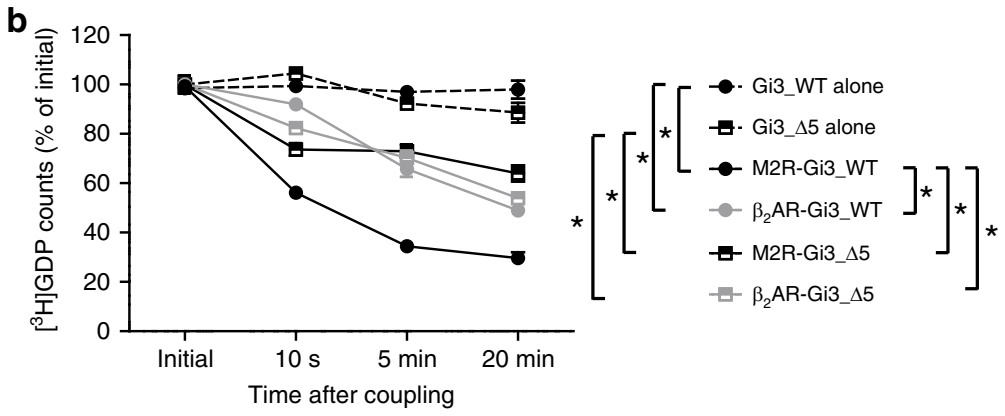

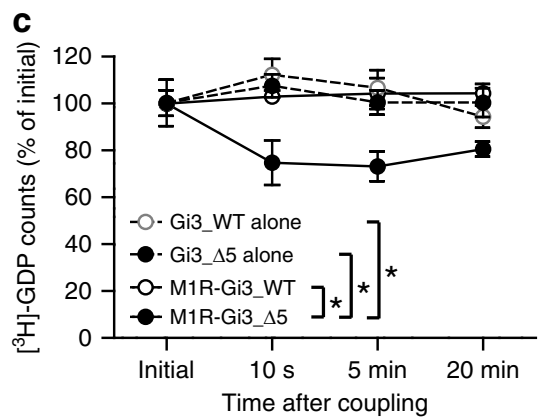
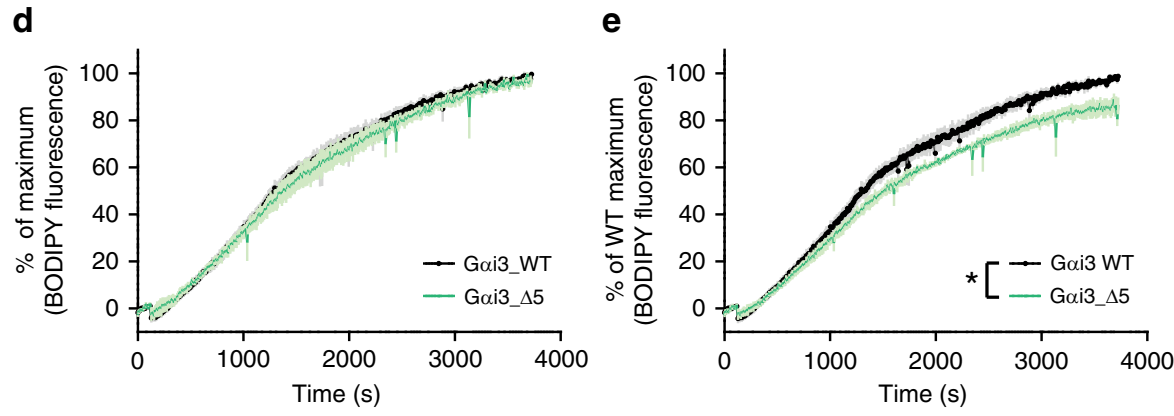

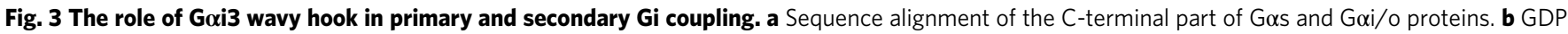
release profiles of Gi3_WT and Gi3__ 5 induced by the M2R or the $\beta_{2} A R$. c GDP release profiles of Gi3_WT and Gi3_ 55 induced by the M1R. For (b) and (c), * indicates statistical differences between groups analyzed by one-way ANOVA test $(p<0.05)$. Error bars represent mean \pm S.E.M of at least three independent experiments $(n=3-6)$. d BODIPY fluorescence presented as percent (\%) of maximum of each sample. e BODIPY fluorescence represented as

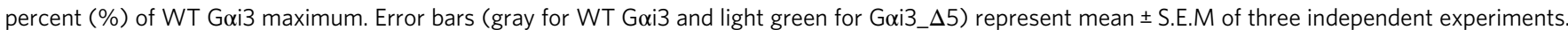
* Indicates statistical differences between groups analyzed by a two-tailed Student's $t$ test $(p<0.05)$. Source data are provided as a Source data file.

higher in WT Gai3 than that in Gai3_ $\Delta 5$ (Fig. 3e). These data suggest that the intrinsic GDP release activity of Gai3_ $\Delta 5$ is not higher than that of WT Gai3, and therefore M1R-induced GDP release from Gi3_ $\Delta 5$ is not due to increased intrinsic GDP release activity.

Gi/o-induced HDX profile changes of M2R and $\boldsymbol{\beta}_{2} \mathrm{AR}$. To gain more insights into the structural changes that occur upon receptor-Gi/o coupling, we compared the HDX levels of the M2R and the $\beta_{2} \mathrm{AR}$ before and after $3 \mathrm{~h}$ of co-incubation with GoA (Fig. $4 \mathrm{a}, \mathrm{b}$, and Supplementary Fig. $4 \mathrm{~b}$ ) and analyzed the timeresolved HDX changes in the M2R and the $\beta_{2} \mathrm{AR}$ during M2R-Gi/ $o$ and $\beta_{2}$ AR-Gi/o coupling (Fig. 4c).

As discussed above, we have previously analyzed the HDX profile changes in the $\beta_{2} \mathrm{AR}$ upon co-incubation with Gs, and observed decreased HDX at ICL2 and the N-terminal region of ICL3 of the $\beta_{2}$ AR (Supplementary Fig. 5a) ${ }^{19}$. The decreased HDX at ICL2 reflects helix formation and interaction of F139 with the hydrophobic pocket of Gas (as shown in Supplementary Fig. 2a, blue dotted box), and the decreased HDX at the N-terminus of ICL3 reflects extended helix formation upon interaction with the C-terminal part of Gas (as shown in Supplementary Fig. 2a, green square).

We could not identify peptides from ICL2 region of the M2R but could analyze the N-terminal region of ICL3. Unlike the $\beta_{2}$ AR-Gs complex, this region did not undergo HDX changes (Fig. 4a). This is consistent with the high-resolution structures of the M2R, where the N-terminal region of ICL3 does not form an extended helix upon interaction with GoA (Supplementary Fig. 4c). Helix 8 (H8) of the M2R showed decreased HDX (Fig. 4a and Supplementary Fig. 4b), which may be caused by the interaction between $\mathrm{H} 8$ and the C-terminal part of Gai/o, as observed in the high-resolution structures of GPCR-Gi/o complexes ${ }^{17}$. Unfortunately, we could not obtain the pulsed
HDX-MS data from $\mathrm{H} 8$, and therefore we could not correlate the time-course of conformational changes between the C-terminal part of Gai/o and M2R H8.

For the $\beta_{2} \mathrm{AR}-\mathrm{Gi} / \mathrm{o}$ complex, when we compared the HDX profiles before and after $3 \mathrm{~h}$ of co-incubation of the $\beta_{2} \mathrm{AR}$ with GoA, HDX levels on the $\beta_{2} \mathrm{AR}$ were not altered at any of the analyzed regions (Fig. 4b). A time-resolved HDX-MS study also showed that the N-terminal region of ICL3 of the $\beta_{2} A R$ does not undergo decreased HDX at any of the tested timepoints during coupling with Gi3 (Fig. 4c, peptides 223-240). A lack of HDX change at the $\mathrm{N}$-terminus of ICL3 suggests that the $\beta_{2} \mathrm{AR}$ fails to form extended helices at the N-terminal region of ICL3 when coupled with $\mathrm{Gi} / \mathrm{o}$. This observation is consistent with the lack of HDX change at the C-terminal part of GaoA or Gai3 (Fig. 1d, Fig. 2, and Supplementary Fig. 5b), which strengthens the hypothesis that the C-terminus of GaoA or Gai3 is not deeply inserted into the $\beta_{2} \mathrm{AR}$ core.

However, time-resolved analysis of HDX profile change showed that the HDX level at ICL2 underwent a transient decrease (within $10 \mathrm{~s}$ of co-incubation) upon co-incubation with Gi3 (Fig. 4c, peptides 133-144). After $10 \mathrm{~s}$, the HDX level was not statistically different either from the $10 \mathrm{~s}$ time point or from the point of $\beta_{2} \mathrm{AR}$ alone. These results suggest that ICL2 engages with Gi3 during an early event, but that the interaction may not be stable.

Importance of ICL2 in primary and secondary Gi/o coupling. Our previous studies suggested that for $\beta_{2}$ AR-Gs coupling, the interaction of a bulky hydrophobic residue, F139 at ICL2, (residue 34.51, based on GPCRdb numbering scheme) with the hydrophobic pocket formed by H41, V217, F219, and F376 (Supplementary Fig. 2a) is the critical step to induce GDP release ${ }^{19,29}$. For example, mutation of Phe139 to Ala in the $\beta_{2} \mathrm{AR}$ (hereafter denoted $\beta_{2}$ AR_F139A) abolished $\beta_{2} A R$-induced GDP release from Gs, although this construct could still interact with $\mathrm{Gs}^{19}$. On 

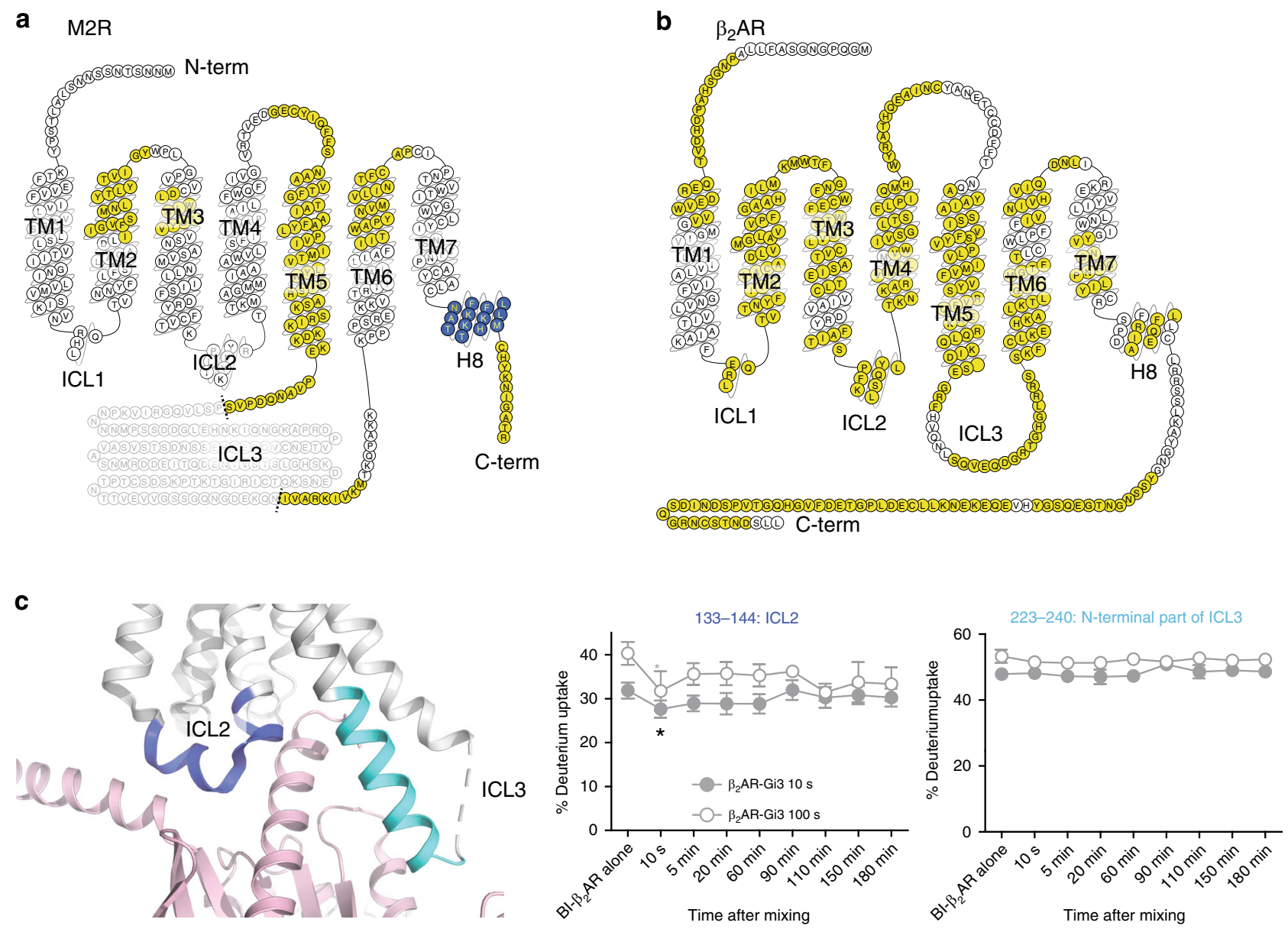

Fig. 4 HDX profiles of the receptors during M2R-GoA and $\boldsymbol{\beta}_{\mathbf{2}} \mathbf{A R}-\mathbf{G o A}$ coupling. $\mathbf{a}, \mathbf{b}$ HDX level changes of the $M 2 R(\mathbf{a})$ and the $\beta_{2} A R(\mathbf{b})$ after $3 \mathrm{~h}$ of incubation with GoA. The changes in HDX are color-coded on the snake maps from GPCRdb (gpcrdb.org). Gray residues in M2R indicate truncated ICL3 for better expression and purification. White residues indicate regions without identified peptides; yellow residues indicate regions without HDX changes; and blue residues indicate regions with decreased HDX upon co-incubation with GoA. c Pulsed HDX-MS analysis of selected peptides of the $\beta_{2} A R$ during $\beta_{2} \mathrm{AR}-\mathrm{Gi} /$ o coupling. The selected peptides analyzed are color-coded on the X-ray crystal structure of $\beta_{2} A R$ (PDB 3SN6) and on the titles of the deuterium uptake graphs. Light pink color represents Gos. Statistically significant changes during coupling were analyzed by repeated-measures ANOVA (rANOVA). To compare two different time points, a two-tailed paired Student's $t$-test was performed, and $p<0.05$ was considered as statistically significant.

* Indicates the first time point that showed a statistical difference compared with pre-incubation. Error bars represent mean \pm S.E.M of three independent experiments. Please note that the data is plotted using a non-linear/non-logarithmic scale.

the other hands, the currently available high-resolution structures of GPCR-Gi/o complexes show that hydrophobic residues at 34.51 form weak hydrophobic interactions with the hydrophobic pocket formed by V34, L194/L195, F196/F197, and F336 of the Gai/o families (Fig. 5a).

To test the role of the interaction of residue 34.51 in primary and secondary GPCR-Gi coupling, we generated mutant constructs in which the bulky hydrophobic residue at 34.51 was replaced with Ala (M2R_L129A and $\beta_{2}$ AR_F139A). M2R_L129A could still induce GDP release from Gi3, albeit to a lesser degree than WT M2R (Fig. 5b). This result is consistent with the previous report in which M2R_L129A induced GDP/GTP turnover, although the degree was reduced to $50 \%$ relative to that in WT M2R ${ }^{16}$. Unlike M2R_L129A-Gi3 coupling, $\beta_{2}$ AR_F139A failed to release GDP from Gi3 (Fig. 5c), which suggests that the bulky hydrophobic residue 34.51 at ICL2 is critical for $\beta_{2}$ AR-Gi3 coupling.

To gain more insights into the role of residue 34.51 in GPCRGi/o coupling, we analyzed the amino acid residue at position 34.51 in class A GPCRs with known coupling G proteins (Supplementary Fig. 1 and Fig. 5d-f). Among the Gs-coupled receptors, $26 \%$ contain Phe or Tyr, and $68 \%$ contain large hydrophobic residues such as Ile, Leu, or Met (Fig. 5d). Thus, a majority (94\%) of Gs-coupled receptors comprise of very large/ large hydrophobic or aromatic ring-containing amino acid residues at position 34.51 . Similarly, a majority $(82 \%)$ of $\mathrm{Gq} / 11$ coupled receptors contain very large/large hydrophobic or aromatic ring-containing amino acid residues at position 34.51 (Fig. 5d). In contrast, the proportion of very large/large hydrophobic or aromatic ring-containing amino acid residues at position 34.51 decreases in Gi/o-coupled receptors (56\%), while the proportion of medium or small hydrophobic amino acids at position 34.51 increases in Gi/o-coupled receptors (25.3\%) (Fig. 5d). Moreover, $17.7 \%$ of Gi/o-coupled receptors contain non-hydrophobic residues (His, Pro, Ser, Thr, Arg, Lys, Glu, and Gln) whereas only $4.5 \%$ of Gs-coupled receptors and $13.1 \%$ of Gq/11-coupled receptors contain these residues (Fig. 5d). These sequence analyses imply that the bulky hydrophobic residue at 34.51 is important for Gs or Gq/11 coupling, but this may not be necessarily true for Gi/o coupling.

We further analyzed amino acids at position 34.51 of all class A Gi/o-coupled receptors (Fig. 5e). Comparison of the 
a

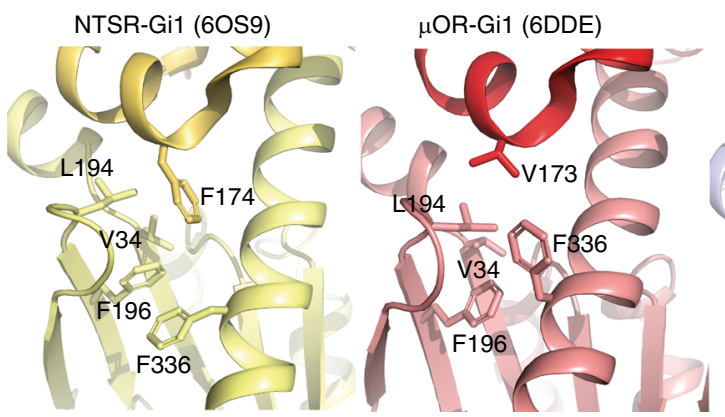

C

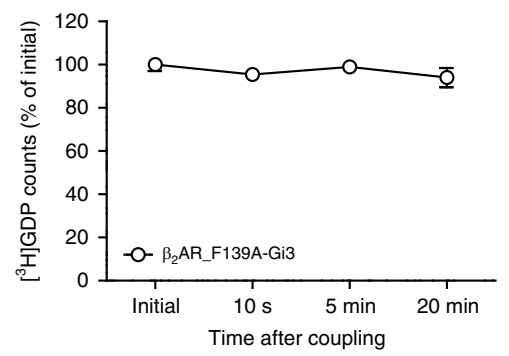

d

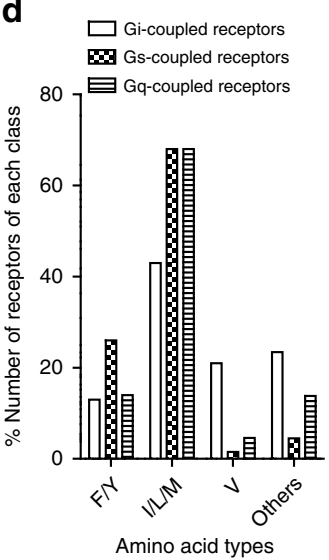

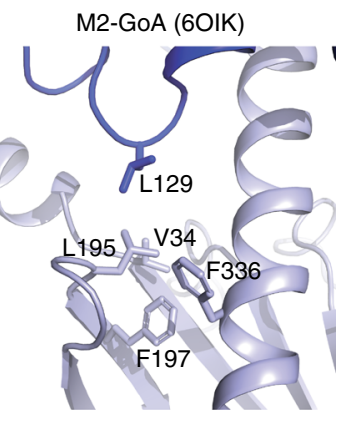

e

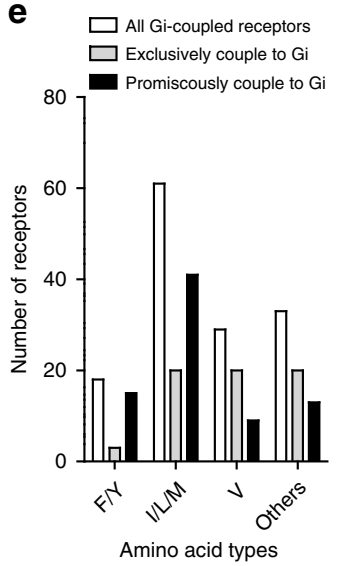

b

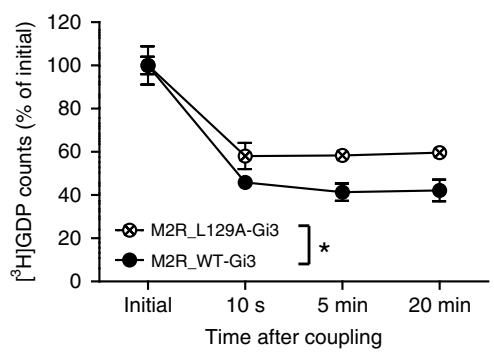

f

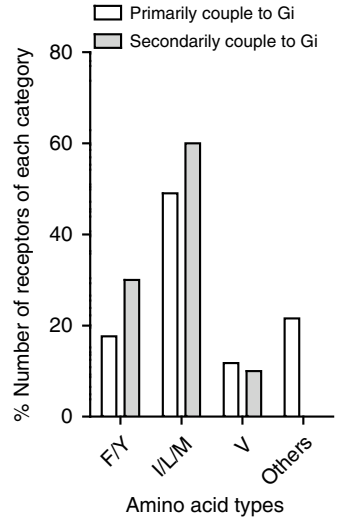

Fig. 5 The role of residue $\mathbf{3 4 . 5 1}$ within ICL2 in M2R-Gi3 and $\boldsymbol{\beta}_{\mathbf{2}} \mathbf{A R}-\mathbf{G i 3}$ coupling. a The structures of ICL2 and hydrophobic pocket of neurotensin receptor-Gi1 complex (left, PDB 6OS9), mu-opioid receptor-Gi1 complex (middle, PDB 6DDE), and M2R-GoA complex (right, PDB 6OIK). Receptors are shown in dark color, and G proteins are shown in light color. b GDP release profiles of M2R-Gi3 and M2R_L129A-Gi3. c GDP release profiles of $\beta_{2} A R \_F 139 A-G i 3$. For $(\mathbf{b})$ and (c), * indicates statistical differences between groups as analyzed by a two-tailed Student's $t$-test $(p<0.05)$. Error bars represent mean \pm S.E.M of three independent experiments. Please note that the data is plotted using a non-linear/non-logarithmic scale. $\mathbf{d}$ Amino acid type analysis at residue 34.51 of type A GPCRs with known coupling G proteins. e Amino acid type analysis at residue 34.51 of type A Gi/o-coupled receptors subcategorized into exclusive or promiscuous coupling. f Amino acid type analysis at residue 34.51 of promiscuously Gi/o-coupled receptors, which are subcategorized into primary and secondary coupling. Source data are provided as a Source data file.

exclusively-Gi/o-coupled and promiscuously-Gi/o-coupled receptors revealed a broad range of amino acid residues in the exclusively-Gi/o-coupled receptors contain, whereas the promiscuously-Gi/o-coupled receptors contain mostly very large/large hydrophobic or aromatic ring-containing amino acid residues (56 receptors out of 78 promiscuously-Gi/o-coupled receptors) (Fig. 5e). When we further subcategorized the promiscuously$\mathrm{Gi} / \mathrm{o}-$ coupled receptors into primarily-Gi/o-coupled receptors and secondarily-Gi/o-coupled receptors, we found that all the receptors that secondarily couple to Gi/o contain Phe/Tyr, Ile/ Leu/Met, or Val and do not contain other amino acids while the receptors that primarily couple to $\mathrm{Gi} / \mathrm{o}$ contain these amino acids as well as other residues such as Ala, His, Pro, Ser/Thr, Arg/Lys, and Gln (Fig. 5f). These findings imply that for the secondary GPCR-Gi/o interaction, the bulky hydrophobic residue at ICL2 may be important, which is consistent with the observation that $\beta_{2}$ AR_F139A failed to release GDP from Gi3 (Fig. 5c).

Taken together, we suggest that the interaction of residue 34.51 with the hydrophobic pocket within the Ga subunit is not critical for primary GPCR-Gi/o coupling, but it is important for secondary GPCR-Gi/o coupling.

\section{Discussion}

Previous studies have suggested that a single receptor differentially activates different $\mathrm{G}$ proteins to varying degrees and/or with different kinetics, which results in complex signal transduction $6,9,30$. This fine-tuning of GPCR-G protein coupling is important for the precise regulation of cellular functions. However, only few studies have suggested the mechanism underlying differential coupling of promiscuous receptors; for example, the availability of $\mathrm{G}$ proteins limits the GPCR-G protein coupling selectivity ${ }^{4,7}$, and different ligand types or ligand concentrations differentially regulate the promiscuity of GPCR-G protein coupling ${ }^{31,32}$.

The current study presents the conformational factors that differentiate between primary and secondary Gi/o-coupling. We found that one of the key structural factors is the engagement of the wavy hook of Gai/o with the receptor (Fig. 6b vs. Fig. 6c). Failure of strong engagement of the wavy hook with the receptor leads to secondary Gi/o coupling (i.e., $\beta_{2} \mathrm{AR}-\mathrm{Gi} / \mathrm{o}, \beta_{2} \mathrm{AR}-\mathrm{Gi} 3 \_\Delta 5$, or M2R-Gi3_ $\Delta 5$ ).

These results are surprising because the engagement of the distal C-terminus of $\mathrm{Ga}$ with receptors has been considered to be critical for GPCR-G protein interaction and coupling selectivity $19,20,33-39$. In our previous study using the $\beta_{2} \mathrm{AR}$ and Gs, truncation of the wavy hook resulted in the complete loss of $\beta_{2} \mathrm{AR}$-induced GDP release, and we suggested that the wavy hook is the initial binding site $^{19}$ (Fig. 6a). However, the present data indicate that the M2R and the $\beta_{2} \mathrm{AR}$ could still couple to the 'wavy hook-truncated' Gai3 (Fig. 3b), and moreover, the M1R, a non-Gi/o-coupled receptor, can induce GDP release from Gi3_ $\Delta 5$ but not from WT Gi3 (Fig. 3c). It is tempting to suggest that the wavy hook of Gi3 facilitates interaction with primary $\mathrm{Gi} / \mathrm{o}$-coupled receptors but inhibits interaction with non-Gi/o-coupled receptors (Fig. 6d). The detailed molecular mechanism of the role of the wavy hook in differentiating primary vs. secondary Gi/o-coupling and preventing interaction with the 
a

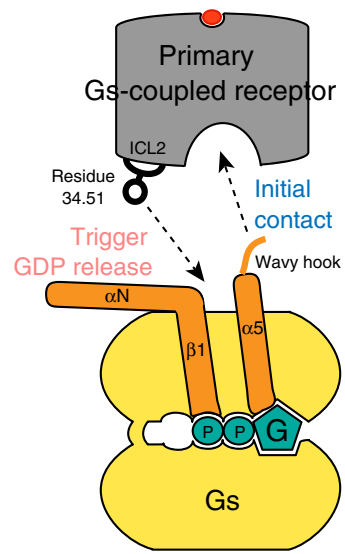

b

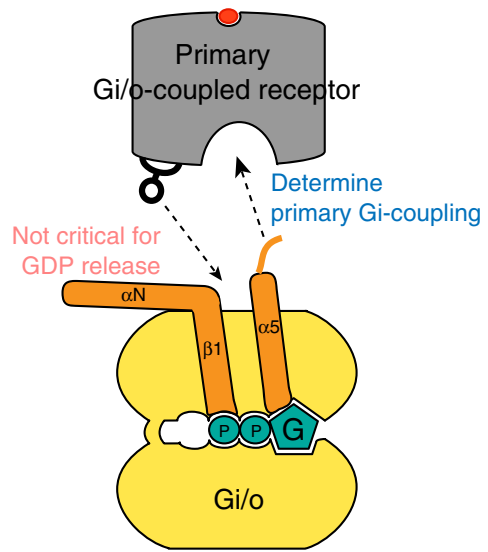

c

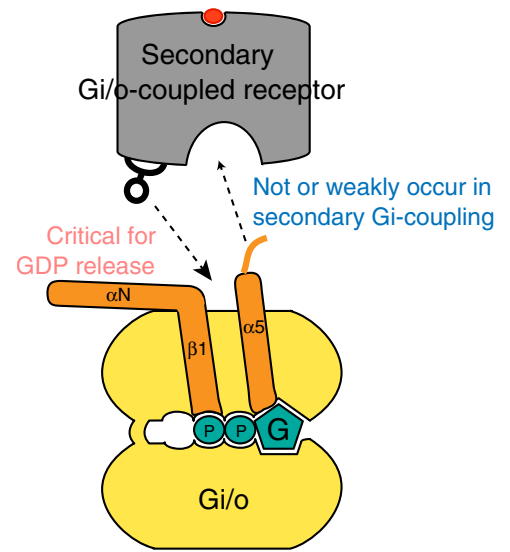

d

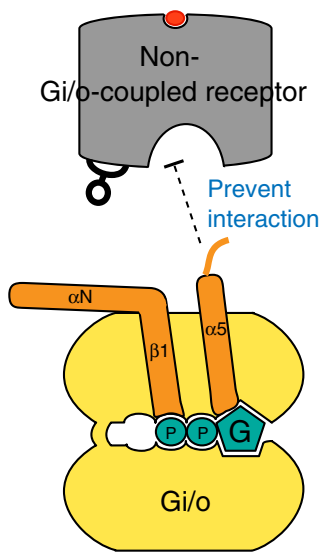

Fig. 6 Summary of Gs and Gi/o coupling mechanisms. a The structural mechanism of primary Gs-coupling based on the study by Du et al. ${ }^{19}$ is illustrated. Wavy hook is the initial contact site with a receptor followed by interaction of residue 34.51 at ICL2 with Gas, which triggers GDP release. b, c The structural mechanism of primary and secondary Gi/o-coupling is illustrated. Interaction of the wavy hook with the receptor determines primary and secondary Gi/o coupling. Interaction of residue 34.51 at ICL2 with Goi/o is critical for secondary Gi/o-coupling but not for primary Gi/o-coupling. d The wavy hook of Goi/o prevents coupling with non-Gi/o-coupled receptors.

non-Gi/o-coupled receptors needs further investigation using systematic mutagenesis or swap mutation of the wavy hook.

Different coupling modes between primary and secondary Gi/ocoupling were also found at receptor residue 34.51 (Fig. 6b vs. Fig. 6c) as the bulky hydrophobic residue at 34.51 is critical for $\beta_{2}$ AR-Gi3 coupling but not for M2R-Gi3 coupling (Fig. 5b, c). Previous studies reported that residue 34.51 within ICL2 of the receptor is critical for receptor-G protein coupling 19,40 . Interestingly, the importance of residue 34.51 has been mostly observed for GPCR-Gs interaction ${ }^{19,40}$ but not for GPCR-Gi/o interaction (Supplementary Fig. 2a vs. Fig. 5a). The analysis of the amino acid type at residue 34.51 supports the hypothesis that the bulky hydrophobic residue at 34.51 is important for primary GPCR-Gs or GPCR-Gq/11 coupling, but may not be critical for primary GPCRGi/o coupling (Fig. 5). Interestingly, all the receptors that secondarily couple to Gi/o contain large hydrophobic amino acids at residue 34.51 (Fig. 5f) suggesting that such amino acids at position 34.51 may be necessary for secondary GPCR-Gi/o coupling.

The current study also suggests that primary Gi/o coupling might follow certain different structural mechanisms compared with primary Gs coupling (Fig. 6a vs Fig. 6b). First, aN showed increased HDX in $\beta_{2}$ AR-Gs coupling and decreased HDX in M2R-Gi3/GoA coupling (Fig. 2 and Supplementary Fig. 5). Second, the $\beta_{2} A R$ failed to induce GDP release from Gs_ $\Delta 5^{19}$, but the M2R still induced GDP release from Gi3_ $\Delta 5$ (Fig. $3 \mathrm{~b}$ ). Third, $\beta_{2} \mathrm{AR} \_$F139A failed to induce GDP release from $\mathrm{Gs}^{19}$, but M2R_L129A still induced GDP release from Gi3 (Fig. 5b). These discrepancies may provide clues to understand GPCR-G protein selectivity, which needs further investigation.

In conclusion, we propose the potential conformational mechanism differentiating primary and secondary Gi/o-coupling and compared the conformational mechanism of primary Gi/ocoupling with that of primary Gs-coupling. The findings raise questions about the detailed functional mechanism of the wavy hook in facilitating primary Gi/o coupling and preventing non$\mathrm{Gi} / \mathrm{o}$ coupling. Moreover, the critical step for GDP release during primary GPCR-Gi/o coupling is remained to be elucidated because the interaction of the residue 34.51 was not critical for GPCR-Gi/o coupling as suggested in GPCR-Gs coupling.

\footnotetext{
Methods

Expression and purification of Gi/o. Following protocol is for expression and purification of samples used for Figs. 1, 2, 4, and 5. Human GaoA or Gai3 was
}

cloned into pFastBac1 vector; $\mathrm{G} \beta 1$ with $3 \mathrm{C}$ protease-cleavable $6 \mathrm{xHis}$-tag and $\mathrm{G} \gamma 2$ were cloned into pFastBac_Dual vector. The G proteins were expressed in High Five insect cells (Expression Systems, 94-001F) using Bac-to-Bac system. Cell cultures were grown at $27^{\circ} \mathrm{C}$ to a density of $3 \times 10^{6}$ cells mL -1 and then infected with Gao or Gai3 and G $\beta 1 \gamma 2$ baculovirus $\left(10-20 \mathrm{~mL} \mathrm{~L}^{-1}\right.$ and $1-2 \mathrm{~mL} \mathrm{~L}^{-1}$ respectively). After $48 \mathrm{~h}$ incubation, the infected cells were harvested by centrifugation and stored at $-80^{\circ} \mathrm{C}$ until use.Cell pellets were resuspended in $100 \mathrm{~mL}$ lysis buffer ( $10 \mathrm{mM}$ Tris, $\mathrm{pH} 7.5,0.1 \mathrm{mM} \mathrm{MgCl} 2,5 \mathrm{mM} \beta$-mercaptoethanol ( $\beta$ $\mathrm{ME}), 10 \mu \mathrm{M}$ GDP, $2.5 \mu \mathrm{g} \mathrm{mL}^{-1}$ leupeptin, and $160 \mu \mathrm{g} \mathrm{mL}-1$ benzamidine) per liter of culture volume and stirred at room temperature for $15 \mathrm{~min}$. Cell membranes were then spun down and resuspended in $100 \mathrm{~mL}$ solubilization buffer $(20 \mathrm{mM}$ HEPEs, $\mathrm{pH} 7.5,100 \mathrm{mM} \mathrm{NaCl}, 1 \%$ sodium cholate, $0.05 \% \mathrm{DDM}, 5 \mathrm{mM} \mathrm{MgCl}$, $2 \mu \mathrm{L}$ CIP, $5 \mathrm{mM} \beta$-ME, $15 \mathrm{mM}$ imidazole, $10 \mu \mathrm{M}$ GDP, $2.5 \mu \mathrm{g} \mathrm{mL}^{-1}$ leupeptin, and $160 \mu \mathrm{g} \mathrm{m}^{-1}$ benzamidine) per liter of culture volume using a Dounce homogenizer. The sample were stirred at $4^{\circ} \mathrm{C}$ for $1 \mathrm{~h}$, and then centrifuged for $20 \mathrm{~min}$ to remove insoluble debris. Nickel-NTA resin $\left(2 \mathrm{~mL} \mathrm{~L}^{-1}\right.$ cell culture) pre-equilibrated in solubilization buffer was added to the supernatant and shaken for $2 \mathrm{~h}$ at $4{ }^{\circ} \mathrm{C}$. After incubation, the Ni-NTA resin was spun down, poured into a glass column, and washed with $50 \mathrm{~mL}$ solubilization buffer. The heterotrimeric GoA or Gi3 was then gradually exchanged into E2 buffer (20 mM HEPEs pH 7.5, $50 \mathrm{mM} \mathrm{NaCl}$, $0.1 \% \mathrm{DDM}, 1 \mathrm{mM} \mathrm{MgCl} 2,5 \mathrm{mM} \beta-\mathrm{ME}, 10 \mu \mathrm{M}$ GDP, $2.5 \mu \mathrm{g} \mathrm{mL}^{-1}$ leupeptin, and $160 \mu \mathrm{gL}^{-1}$ benzamidine). The protein was then eluted with E2 buffer supplemented with $250 \mathrm{mM}$ imidazole. The protein was then dephosphorylated by treating with $5 \mu \mathrm{L}$ lamda phosphatase (supplemented with $1 \mathrm{mM} \mathrm{MnCl} 2$ for activity), $1 \mu \mathrm{L}$ CIP, and $1 \mu \mathrm{L}$ Antarctic phosphatase, then incubated at $4{ }^{\circ} \mathrm{C}$ overnight. The $6 \mathrm{xHis-tag}$ was removed using $3 \mathrm{C}$ protease. Cleaved GoA or Gi3 was purified by an additional negative Ni-NTA purification step. The Ni-NTA chromatography purified GoA or Gi3 was further purified with MonoQ column (GE Healthcare). The peak fractions of MonoQ column were collected and concentrated using a $50 \mathrm{kDa}$ molecular weight cutoff Millipore concentrator. The concentrated heterotrimeric GoA or Gi3 was aliquoted, flash frozen in liquid nitrogen and frozen at $-80^{\circ} \mathrm{C}$ before use.

Expression and purification of WT and mutant Goi3__5. Following protocol is for expression and purification of samples used for Fig. 3. The recombinant Gai/o protein containing $\mathrm{N}$-terminal His-tag and TEV cleavage site was constructed in pET21a. Gai3_ $\Delta 5$ mutant was generated by site-directed mutagenesis using PCR. The primers used for mutagenesis are listed in Supplementary Table 1. Gai3 and Gai3_ $\Delta 5$ were transformed into Escherichia coli LOBSTR (Kerafast, EC1002) and GaoA was transformed into Escherichia coli BL21-DE3 (iNtRON, ITY-YE207). Cells were grown in Terrific Broth in the presence of antibiotic at $37^{\circ} \mathrm{C}$ until $\mathrm{OD}_{600}$ reached $0.6-0.8$. Protein expression was induced by $0.03 \mathrm{mM}$ IPTG and cells were further incubated at $16^{\circ} \mathrm{C}$ for $24 \mathrm{~h}$. For protein purification, the cell pellets were harvested and resuspended in lysis buffer (20 mM HEPES pH 7.4, $300 \mathrm{mM} \mathrm{NaCl}$, $2 \mathrm{mM} \mathrm{MgCl}_{2}, 20 \mu \mathrm{M}$ GDP, 1:1000 protease inhibitor cocktail, $2.5 \mu \mathrm{g} \mathrm{ml}^{-1}$ leupeptin, $10 \mu \mathrm{g} \mathrm{ml}^{-1}$ benzamidine, $100 \mu \mathrm{M} \mathrm{TCEP}$, and $10 \%$ glycerol) in three folds of cell pellet volume and incubated with $5 \mathrm{mg} \mathrm{mL}^{-1}$ lysozyme for $30 \mathrm{~min}$ at room temperature. The lysate was then incubated with $10 \mu \mathrm{g} \mathrm{mL}^{-1}$ DNasel for another $30 \mathrm{~min}$. The supernatant was collected by centrifugation at $20,000 \times g$ for $30 \mathrm{~min}$ at $4{ }^{\circ} \mathrm{C}$, supplemented with $20 \mathrm{mM}$ imidazole, and loaded onto Ni-NTA column equilibrated with lysis buffer containing $20 \mathrm{mM}$ imidazole. The Ni-NTA resin was washed with wash buffer (20 mM HEPES pH 7.4, $300 \mathrm{mM} \mathrm{NaCl}, 2 \mathrm{mM} \mathrm{MgCl}_{2}$, 
$20 \mu \mathrm{M}$ GDP, 1:1000 protease inhibitor cocktail, $2.5 \mu \mathrm{g} \mathrm{mL}^{-1}$ leupeptin, $10 \mu \mathrm{g} \mathrm{mL}^{-1}$ benzamidine, $100 \mu \mathrm{M}$ TCEP, and $20 \mathrm{mM}$ imidazole). The proteins were eluted with elution buffer (20 mM HEPES pH 7.4, $300 \mathrm{mM} \mathrm{NaCl}, 2 \mathrm{mM} \mathrm{MgCl} 2,20 \mu \mathrm{M}$ GDP, 1:1000 protease inhibitor cocktail, $2.5 \mu \mathrm{g} \mathrm{mL}^{-1}$ leupeptin, $10 \mu \mathrm{g} \mathrm{mL}^{-1}$ benzamidine, $100 \mu \mathrm{M}$ TCEP, and $250 \mathrm{mM}$ imidazole). Proteins were further purified using a Superdex-200 (10/300) column with ÄKTA FPLC. The protein fractions were collected by monitoring the absorbance at $280 \mathrm{~nm}$. Proteins were then concentrated, supplemented with $20 \%$ glycerol, and stored at $-80^{\circ} \mathrm{C}$ until further use.

\section{Expression and purification of the M2R and the M1R. Human M2R and M1R} genes, containing N-terminal FLAG-tag and C-terminal His-tag, were subcloned into pFastBacl vector. The L129A mutation of M2R was generated by QuickChange mutagenesis and confirmed by DNA sequencing. The primers used for mutagenesis are listed in Supplementary Table 1. All M2R and M1R constructs used in this study were expressed in Sf9 insect cells (Expression Systems, 94-002F) using the Bac-to-Bac baculovirus system. Sf9 cells were grown in the ESF 921 medium and were infected with recombinant baculovirus at a density of $4 \times 10^{6}$ cells $\mathrm{mL}^{-1}$, in the presence of $10 \mu \mathrm{M}$ atropine. The cells were harvested after $48 \mathrm{~h}$ of infection at $27^{\circ} \mathrm{C}$. Cell pellets were lysed using a lysis buffer $(10 \mathrm{mM}$ Tris $\mathrm{pH} 7.5$, $1 \mathrm{mM}$ EDTA, $10 \mu \mathrm{M}$ atropine, $2.5 \mu \mathrm{g} \mathrm{mL}^{-1}$ leupeptin, and $160 \mu \mathrm{g} \mathrm{mL} \mathrm{m}^{-1}$ benzamidine). Cell membranes were then spun down and solubilized with a buffer containing $20 \mathrm{mM}$ HEPES (pH 7.5), $750 \mathrm{mM} \mathrm{NaCl}, 1 \% \mathrm{DDM}, 0.2 \%$ sodium cholate, $0.03 \% \mathrm{CHS}, 10 \mu \mathrm{M}$ atropine, $2.5 \mu \mathrm{g} \mathrm{mL}-1$ leupeptin, $160 \mu \mathrm{g} \mathrm{mL} \mathrm{m}^{-1}$ benzamidine, and $30 \%$ glycerol. The solubilized receptor was then purified through $\mathrm{Ni}$ NTA chromatography and eluted with a buffer containing 20 mM HEPES (pH 7.5), $750 \mathrm{mM} \mathrm{NaCl}, 0.1 \% \mathrm{DDM}, 0.02 \%$ sodium cholate, $0.03 \% \mathrm{CHS}, 10 \mu \mathrm{M}$ atropine, and $30 \%$ glycerol and supplemented with $250 \mathrm{mM}$ imidazole. The Ni-NTA purified receptor was then loaded onto an anti-FLAG column with M1 affinity resin and washed extensively with a buffer containing $20 \mathrm{mM}$ HEPES ( $\mathrm{pH} 7.5$ ), $750 \mathrm{mM}$ $\mathrm{NaCl}, 0.1 \% \mathrm{DDM}, 0.02 \%$ sodium cholate, $0.003 \% \mathrm{CHS}$, and $10 \mu \mathrm{M}$ iperoxo and supplemented with $2 \mathrm{mM} \mathrm{CaCl}_{2}$. Thereafter, it was eluted with the same buffer supplemented with $0.2 \mathrm{mg} \mathrm{mL}^{-1}$ of FLAG peptide and $5 \mathrm{mM}$ of EDTA. The antiFLAG-chromatography-purified receptor was finally purified by size exclusion chromatography against a buffer containing $20 \mathrm{mM}$ HEPES (pH 7.5), $100 \mathrm{mM}$ $\mathrm{NaCl}, 0.1 \% \mathrm{DDM}, 0.003 \% \mathrm{CHS}$, and $10 \mu \mathrm{M}$ iperoxo. The monodisperse peak fractions were concentrated, flash frozen, and stored at $-80^{\circ} \mathrm{C}$ until further use

Expression and purification of the $\boldsymbol{\beta}_{\mathbf{2}} \mathbf{A R}$. The $\beta_{2} \mathrm{AR}$ was expressed in Sf9 insect cells (Expression Systems, 94-002F) using the BestBac expression system. The F139A mutation was generated by Quick-Change mutagenesis and confirmed by DNA sequencing. The primers used for mutagenesis are listed in Supplementary Table 1. Proteins were expressed by infecting sf 9 cells at $4 \times 10^{6}$ cells $\mathrm{mL}^{-1}$ with second-passage baculovirus using $20 \mathrm{~mL} \mathrm{~L}^{-1}$ of cell culture supplemented with $2 \mu \mathrm{M}$ alprenolol. The cells were harvested after $48 \mathrm{~h}$ incubation at $27^{\circ} \mathrm{C}$. Cell pellets were resuspended in lysis buffer (20 mM HEPES pH 7.5, $5 \mathrm{mM}$ EDTA, $1 \mu \mathrm{M}$ alprenolol, $2.5 \mu \mathrm{g} \mathrm{mL}^{-1}$ leupeptin, and $160 \mu \mathrm{g} \mathrm{mL}^{-1}$ benzamidine) at $10 \mathrm{~mL} \mathrm{~g}^{-1}$ of cell pellet and stirred for $15 \mathrm{~min}$. The collected cell membrane was then homogenized by a Douncer device with the sample in solubilization buffer $(20 \mathrm{mM}$ HEPES, pH 7.5, $100 \mathrm{mM} \mathrm{NaCl}, 1 \%$ DDM, $1 \mu \mathrm{M}$ alprenolol, $2.5 \mu \mathrm{g} \mathrm{mL} \mathrm{m}^{-1}$ leupeptin, and $160 \mu \mathrm{g} \mathrm{mL}^{-1}$ benzamidine) for $1 \mathrm{~h}$ at room temperature to extract the receptor. After adding $2 \mathrm{mM} \mathrm{CaCl}_{2}$, the supernatant was collected by centrifugation at $18,000 \times g$ for $30 \mathrm{~min}$ and loaded onto anti-FLAG column with M1-antibody resin. The column was thoroughly washed with HMS-CHS buffer (20 mM HEPES pH $7.5,350 \mathrm{mM} \mathrm{NaCl}, 0.1 \%$ DDM, and $0.01 \%$ cholesterol hemisuccinate) supplemented with $2 \mathrm{mM} \mathrm{CaCl}_{2}$. The receptor was then eluted with HMS-CHS buffer supplemented with $5 \mathrm{mM}$ EDTA and $200 \mu \mathrm{g} \mathrm{mL}^{-1}$ FLAG peptide. The eluted protein was kept frozen and thawed immediately prior to use. The thawed receptor was further purified via alprenolol-Sepharose affinity chromatography using HMSCHS buffer with $300 \mu \mathrm{M}$ alprenolol as the elution buffer. The eluted receptors were once again loaded onto anti-FLAG column and washed with HMS-CHS buffer to achieve unliganded receptors by removing alprenolol. The bound receptor was then eluted with HMS-CHS buffer with $5 \mathrm{mM}$ EDTA, $200 \mu \mathrm{g} \mathrm{ml}^{-1}$ FLAG peptide and $10 \mu \mathrm{M}$ BI-167107. The functional receptors were further purified by size exclusion chromatography using a Superdex-200 column in HLS-CHS buffer $20 \mathrm{mM}$ HEPES $\mathrm{pH} 7.5,150 \mathrm{mM} \mathrm{NaCl}, 0.1 \%$ DDM, 0.01\% CHS, $2 \mu \mathrm{M}$ BI-167107. The receptors were concentrated, flash frozen in liquid nitrogen, and stored at $-80^{\circ} \mathrm{C}$ until use.

GPCR-Gi/o complex formation and HDX-MS. To form GPCR-Gi/o complex, $\mathrm{Gi} / \mathrm{o}(65 \mu \mathrm{M})$ was mixed with 1.15-fold molar excess of iperoxo-bound M2R or BI167107-bound $\beta_{2} \mathrm{AR}$ at room temperature. Apyrase $\left(200 \mathrm{mU} \mathrm{mL}^{-1}\right)$ was added after $90 \mathrm{~min}$ of incubation to hydrolyze GDP, and to generate a stable complex. For continuous labeling deuterium exchange, $5 \mu \mathrm{L}$ of complex, agonist bound receptor or GDP-bound Gi/o was mixed with $25 \mu \mathrm{L}$ of $\mathrm{D}_{2} \mathrm{O}$ buffer $(20 \mathrm{mM}$ HEPES (pD 7.4), $100 \mathrm{mM} \mathrm{NaCl}, 100 \mathrm{mM}$ TCEP, and $0.1 \%$ DDM supplemented with $5 \mu \mathrm{M}$ agonist, $20 \mu \mathrm{M}$ GDP, or both for receptor alone, G protein alone, or complex, respectively) and incubated for 10,100,1000, and 10,000 s at room temperature. For pulselabeling deuterium exchange, GPCR and Gi/o were mixed at room temperature as described above, and $5 \mu \mathrm{L}$ aliquots were collected at the indicated time points (before mixing, $10 \mathrm{~s}, 5 \mathrm{~min}, 20 \mathrm{~min}, 60 \mathrm{~min}, 90 \mathrm{~min}, 110 \mathrm{~min}, 150 \mathrm{~min}$, and $180 \mathrm{~min}$ ), mixed with $25 \mu \mathrm{L}$ of $\mathrm{D}_{2} \mathrm{O}$ buffer, and incubated for $10 \mathrm{~s}$ or $100 \mathrm{~s}$ at room temperature. The deuterated samples were quenched using $30 \mu \mathrm{L}$ of ice-cold quench buffer $\left(0.1 \mathrm{M} \mathrm{NaH}_{2} \mathrm{PO}_{4}\right.$ and $20 \mathrm{mM}$ TCEP (pH 2.01)), snap-frozen on dry ice, and stored at $-80^{\circ} \mathrm{C}$. Non-deuterated samples were prepared by mixing $5 \mu \mathrm{L}$ of protein sample with $25 \mu \mathrm{L}$ of their respective $\mathrm{H}_{2} \mathrm{O}$ buffers, followed by quenching and freezing, as described above.

The quenched samples were digested and isolated using the HDX-UPLC-ESIMS system (Waters, Milford, MA, USA). Briefly the quenched samples were thawed and immediately injected to an immobilized pepsin column $(2.1 \times 30 \mathrm{~mm})$ (Life Technologies, Carlsbad, CA, USA) at a flow rate of $100 \mu \mathrm{L} \mathrm{min}^{-1}$ in $0.05 \%$ formic acid in $\mathrm{H}_{2} \mathrm{O}$ at $12^{\circ} \mathrm{C}$. The peptic peptides were then collected on a C18 VanGuard trap column $(1.7 \mu \mathrm{m} \times 30 \mathrm{~mm})$ (Waters) for desalting with $0.05 \%$ formic in $\mathrm{H}_{2} \mathrm{O}$ and subsequently separated by ultra-pressure liquid chromatography using an Acquity UPLC C18 column $(1.7 \mu \mathrm{m}, 1.0 \times 100 \mathrm{~mm})$ (Waters) at a flow rate of $40 \mu \mathrm{L}$ min $^{-1}$ with an acetonitrile gradient starting from 8 to $85 \%$ over 8.5 min using two pumps. The mobile phase A was $0.1 \%$ formic acid in $\mathrm{H}_{2} \mathrm{O}$ and the mobile phase $\mathrm{B}$ was $0.1 \%$ formic acid in acetonitrile. Buffers were adjusted to $\mathrm{pH} 2.5$ and the system was maintained at $0.5^{\circ} \mathrm{C}$ (except pepsin digestion was performed at $12^{\circ} \mathrm{C}$ ) to minimize the back-exchange of deuterium to hydrogen. Mass spectra were analyzed by Xevo G2 quadrupole-time of flight (Q-TOF) equipped with a standard electrospray ionization (ESI) source in $\mathrm{MS}^{\mathrm{E}}$ mode (Waters) with positive ion mode. The capillary, cone, and extraction cone voltages were set to $3 \mathrm{kV}, 40 \mathrm{~V}$, and $4 \mathrm{~V}$, respectively. Source and desolvation temperatures were set to $120^{\circ} \mathrm{C}$ and $350{ }^{\circ} \mathrm{C}$, respectively. Trap and transfer collision energies were set to $6 \mathrm{~V}$, and the trap gas flow was set to $0.3 \mathrm{~mL} \mathrm{~min}^{-1}$. The mass spectrometer was calibrated with sodium iodide solution $\left(2 \mu \mathrm{g} \mu \mathrm{L}^{-1}\right)$. [Glu1]-Fibrinopeptide B solution $\left(200 \mathrm{fg} \mu \mathrm{L}^{-1}\right)$ in $\mathrm{MeOH}$ :water $(50: 50(\mathrm{v} / \mathrm{v})+1 \%$ acetic acid) was utilized for the lock-mass correction and the ions at mass-to-charge ration $(\mathrm{m} / \mathrm{z}) 785.8427$ were monitored at scan time $0.1 \mathrm{~s}$ with a mass window of $\pm 0.5 \mathrm{Da}$. The reference internal calibrant was introduced at a flow rate of $20 \mu \mathrm{L} \mathrm{min}{ }^{-1}$ using the lock mass sprayer and the acquired spectra were automatically corrected using the lock-mass. Two independent interleaved acquisitions were automatically created: the first function, typically set at $4 \mathrm{eV}$, collected low energy or unfragmented data while the second function collected high energy or fragmented data typically obtained by using a collision ramp from $30-55 \mathrm{eV}$. Ar gas was used for collision induced dissociation (CID). Mass spectral were acquired in the range of $\mathrm{m} / \mathrm{z} 100-2000$ for $10 \mathrm{~min}$. ProteinLynx Global Server 2.4 (Waters) was utilized to identify peptic peptides from the non-deuterated samples with variable methionine oxidation modification and a peptide score of 6. DynamX 2.0 software (Waters) was used to determine the level of deuterium uptake for each peptide by measuring the centroid of isotopic distribution. The average back-exchange in our system was $\sim 30-40 \%$, but we did not correct for back exchange because the proteins aggregate in fully deuterated samples. All the data were derived from at least three independent experiments. The detailed HDX-MS results are summarized in the supplementary data, which were generated according to Masson et al.'s recommendation ${ }^{41}$.

GDP release assay. Purified Ga subunit ( $200 \mathrm{nM}$ ) of each $\mathrm{G}$ protein (GoA or Gi3) was mixed with $50 \mathrm{nM}$ of $\left[{ }^{3} \mathrm{H}\right] \mathrm{GDP}$ for $1 \mathrm{~h}$ at room temperature, in a buffer containing $20 \mathrm{mM}$ HEPES (pH 7.5), $100 \mathrm{mM} \mathrm{NaCl}, 0.1 \%$ DDM, $100 \mu \mathrm{M}$ TCEP, and $2 \mu \mathrm{M}$ GDP. Thereafter, $2 \mu \mathrm{M}$ of purified $\mathrm{G} \beta \gamma$ was added. After $10 \mathrm{~min}$ of incubation, $5 \mu \mathrm{M}$ of BI-167107-bound $\beta_{2} \mathrm{AR}$, iperoxo-bound $\mathrm{M} 2 \mathrm{R}$, or the corre sponding DDM buffer, of similar volume, was further added to initiate GDP release, in the presence of $1 \mu \mathrm{M}$ GDP. The reaction mixture was aliquoted at indicated time points, and immediately loaded onto calibrated G-50 columns. The flow through was collected with $1.1 \mathrm{~mL}$ of buffer (20 mM HEPES (pH 7.5), $100 \mathrm{mM}$ $\mathrm{NaCl}$, and $0.1 \% \mathrm{DDM}$ ), and GoA- or Gi3-bound $\left[{ }^{3} \mathrm{H}\right] \mathrm{GDP}$ was measured using a scintillation counter (Beckman Coulter, Brea, CA, USA), after adding $15 \mathrm{~mL}$ of scintillation fluid. The initial sample represents $\left[{ }^{3} \mathrm{H}\right] \mathrm{GDP}$ binding capacity of GoA or Gi3, before initiation of GDP release.

BODIPY-GTP $\gamma \mathbf{S}$ assay. Nucleotide binding to GaoA and Gai3 were determined by measuring change in fluorescence intensity of BODIPY-FL-GTP $\gamma \mathrm{S}$ (Thermo Fisher Scientific, Waltham, MA, USA) in an imaging buffer comprised of $20 \mathrm{mM}$ Tris- $\mathrm{HCl}$ ( $\mathrm{pH} 8.0$ ), $1 \mathrm{mM}$ EDTA, $10 \mathrm{mM} \mathrm{MgCl}_{2}$, and $100 \mu \mathrm{M}$ TCEP. The fluorophore was excited at $485 \mathrm{~nm}$ (bandwidth $14 \mathrm{~nm}$ ) and the emission spectrum was recorded at $535 \mathrm{~nm}$ (bandwidth $25 \mathrm{~nm}$ ) using TriStar2 S LB 942 Multimode Microplate Reader (Berthold, Germany). Baseline in absence of protein samples was determined by measuring fluorescence intensity of imaging buffer with or without $50 \mathrm{nM}$ BODIPY-FL-GTP $\gamma \mathrm{S}$ for $120 \mathrm{~s}$. GaoA and Gai3 prepared in $20 \mathrm{mM}$ HEPES (pH 7.4), $100 \mathrm{mM} \mathrm{NaCl}, 2 \mathrm{mM} \mathrm{MgCl}, 100 \mu \mathrm{M}$ TCEP, and $10 \mu \mathrm{M}$ GDP were mixed with imaging buffer with or without $50 \mathrm{nM}$ BODIPY-FL-GTP $\gamma \mathrm{S}$ in 1:10 dilution $(1.5 \mu \mathrm{M}$ final GaoA and Gai3 concentration). The changes in fluorescence were measured for $60 \mathrm{~min}$. Data points were collected every $10 \mathrm{~s}$ using a 96-well black plate. All steps were carried out at room temperature. The spectra were corrected by measurements in absence of BODIPY-FL-GTP $\gamma S$ and normalized by setting the peak fluorescence of BODIPY-FL-GTP $\gamma$ S in presence of protein as 100 . 
Statistics and reproducibility. Results are representatives of at least three independent experiments and are expressed as mean \pm S.E.M. Statistical analysis was performed using GraphPad Prism software (San Diego, CA, USA). Statistical significance of time-dependent changes was determined by repeated-measures oneway ANOVA (rANOVA) at an a level $=0.01$ followed by Turkey's multiple comparison test; change in a time series as a whole was considered significant when the F statistic was $>1$. The significance of differences between two different time points within series or two groups was determined by paired or unpaired two-tailed Student's $t$-test. The significance of differences between more than two groups was determined by one-way ANOVA. Analysis was considered significant at $p<0.05$.

Reporting summary. Further information on research design is available in the Nature Research Reporting Summary linked to this article.

\section{Data availability}

Data supporting the findings of this manuscript are available from the corresponding authors upon reasonable request. A reporting summary for this Article is available as a Supplementary Information file.

HDX-MS data have been deposited to ProteomeXchange Consortium ${ }^{42}$ via PRIDE $^{43}$ partner repository with the set identifier PXD019367. The source data underlying Figs. $1 \mathrm{~b}, 3 \mathrm{~b}-\mathrm{e}$, and $5 \mathrm{~b}-\mathrm{f}$ are provided as a Source Data file. Data for sequence analysis in Fig. $5 \mathrm{~d}-\mathrm{f}$ are available from GPCR database (gpcrdb.org).

Received: 4 February 2020; Accepted: 4 June 2020;

Published online: 22 June 2020

\section{References}

1. Syrovatkina, V., Alegre, K. O., Dey, R. \& Huang, X. Y. Regulation, signaling, and physiological functions of G-proteins. J. Mol. Biol. 428, 3850-3868 (2016).

2. Milligan, G. \& Kostenis, E. Heterotrimeric G-proteins: a short history. Br. J. Pharm. 147, S46-S55 (2006).

3. Mahoney, J. P. \& Sunahara, R. K. Mechanistic insights into GPCR-G protein interactions. Curr. Opin. Struct. Biol. 41, 247-254 (2016).

4. Milligan, $\mathrm{G}$. Is promiscuity of $\mathrm{G}$ protein interaction an issue in the classification of receptors? Ann. N. Y Acad. Sci. 812, 126-132 (1997).

5. Albert, P. R. \& Robillard, L. G protein specificity: traffic direction required. Cell Signal 14, 407-418 (2002).

6. Woehler, A. \& Ponimaskin, E. G. G protein-mediated signaling: same receptor, multiple effectors. Curr. Mol. Pharm. 2, 237-248 (2009).

7. Nasman, J., Kukkonen, J. P., Ammoun, S. \& Akerman, K. E. Role of G-protein availability in differential signaling by alpha 2 -adrenoceptors. Biochem Pharm. 62, 913-922 (2001)

8. Xiao, R. P. Beta-adrenergic signaling in the heart: dual coupling of the beta2adrenergic receptor to $\mathrm{G}(\mathrm{s})$ and $\mathrm{G}(\mathrm{i})$ proteins. Sci. STKE 2001, re15 (2001).

9. Ayoub, M. A., Trinquet, E., Pfleger, K. D. \& Pin, J. P. Differential association modes of the thrombin receptor PAR1 with Galphail, Galpha12, and betaarrestin 1. FASEB J. 24, 3522-3535 (2010).

10. Hamamoto, A., Kobayashi, Y. \& Saito, Y. Identification of amino acids that are selectively involved in $\mathrm{Gi} / \mathrm{o}$ activation by rat melanin-concentrating hormone receptor 1. Cell Signal 27, 818-827 (2015).

11. Harding, S. D. et al. The IUPHAR/BPS Guide to PHARMACOLOGY in 2018: updates and expansion to encompass the new guide to IMMUNOPHARMACOLOGY. Nucleic Acids Res. 46, D1091-D1106 (2018).

12. Inoue, A. et al. Illuminating G-protein-coupling selectivity of GPCRs. Cell 177, 1933-1947.e1925 (2019).

13. Liang, Y. L. et al. Phase-plate cryo-EM structure of a class B GPCR-G-protein complex. Nature 546, 118-123 (2017).

14. Carpenter, B., Nehme, R., Warne, T., Leslie, A. G. \& Tate, C. G. Structure of the adenosine $\mathrm{A}(2 \mathrm{~A})$ receptor bound to an engineered $\mathrm{G}$ protein. Nature 536, 104-107 (2016).

15. Rasmussen, S. G. et al. Crystal structure of the beta2 adrenergic receptor-Gs protein complex. Nature 477, 549-555 (2011).

16. Maeda, S., Qu, Q., Robertson, M. J., Skiniotis, G. \& Kobilka, B. K. Structures of the M1 and M2 muscarinic acetylcholine receptor/G-protein complexes. Science 364, 552-557 (2019).

17. Garcia-Nafria, J. \& Tate, C. G. Cryo-EM structures of GPCRs coupled to Gs, Gi and Go. Mol. Cell Endocrinol. 488, 1-13 (2019).

18. Gulukhova, A. et al. Rules of engagement: GPCRs and G proteins. ACS Pharmacol. Transl. Sci. 1, 73-83 (2018).

19. Du, Y. et al. Assembly of a GPCR-G protein complex. Cell 177, 1232-1242. e1211 (2019)

20. Okashah, N. et al. Variable G protein determinants of GPCR coupling selectivity. Proc. Natl Acad. Sci. USA 116, 12054-12059 (2019).
21. Strohman, M. J. et al. Local membrane charge regulates beta2 adrenergic receptor coupling to Gi3. Nat. Commun. 10, 2234 (2019).

22. Casella, I., Ambrosio, C., Gro, M. C., Molinari, P. \& Costa, T. Divergent agonist selectivity in activating beta1- and beta2-adrenoceptors for G-protein and arrestin coupling. Biochem J. 438, 191-202 (2011).

23. Griffin, M. T., Figueroa, K. W., Liller, S. \& Ehlert, F. J. Estimation of agonis activity at $\mathrm{G}$ protein-coupled receptors: analysis of M2 muscarinic receptor signaling through Gi/o,Gs, and G15. J. Pharm. Exp. Ther. 321, 1193-1207 (2007).

24. Peralta, E. G., Ashkenazi, A., Winslow, J. W., Ramachandran, J. \& Capon, D. J. Differential regulation of PI hydrolysis and adenylyl cyclase by muscarinic receptor subtypes. Nature 334, 434-437 (1988).

25. Chung, K. Y. et al. Conformational changes in the G protein Gs induced by the beta2 adrenergic receptor. Nature 477, 611-615 (2011).

26. Westfield, G. H. et al. Structural flexibility of the $G$ alpha s alpha-helical domain in the beta2-adrenoceptor Gs complex. Proc. Natl Acad. Sci. USA 108, 16086-16091 (2011)

27. Tontson, L., Babina, A., Vosumaa, T., Kopanchuk, S. \& Rinken, A. Characterization of heterotrimeric nucleotide-depleted Galpha(i)-proteins by Bodipy-FL-GTPgammaS fluorescence anisotropy. Arch. Biochem. Biophys. 524, 93-98 (2012).

28. McEwen, D. P., Gee, K. R., Kang, H. C. \& Neubig, R. R. Fluorescent BODIPYGTP analogs: real-time measurement of nucleotide binding to $\mathrm{G}$ proteins. Anal. Biochem. 291, 109-117 (2001).

29. Preininger, A. M., Meiler, J. \& Hamm, H. E. Conformational flexibility and structural dynamics in GPCR-mediated G protein activation: a perspective. $J$. Mol. Biol. 425, 2288-2298 (2013)

30. Hermans, E. Biochemical and pharmacological control of the multiplicity of coupling at G-protein-coupled receptors. Pharm. Ther. 99, 25-44 (2003).

31. Cordeaux, Y., Ijzerman, A. P. \& Hill, S. J. Coupling of the human A1 adenosine receptor to different heterotrimeric $\mathrm{G}$ proteins: evidence for agonist-specific G protein activation. Br. J. Pharm. 143, 705-714 (2004).

32. Arai, K. et al. Differential requirement of $G$ alpha12, $G$ alpha13, G alphaq, and $\mathrm{G}$ beta gamma for endothelin-1-induced c-Jun NH2-terminal kinase and extracellular signal-regulated kinase activation. Mol. Pharm. 63, 478-488 (2003)

33. Flock, T. et al. Selectivity determinants of GPCR-G-protein binding. Nature 545, 317-322 (2017).

34. Conklin, B. R., Farfel, Z., Lustig, K. D., Julius, D. \& Bourne, H. R. Substitution of three amino acids switches receptor specificity of $\mathrm{Gq}$ alpha to that of $\mathrm{Gi}$ alpha. Nature 363, 274-276 (1993).

35. Hamm, H. E. et al. Site of G protein binding to rhodopsin mapped with synthetic peptides from the alpha subunit. Science 241, 832-835 (1988).

36. Rose, A. S. et al. Position of transmembrane helix 6 determines receptor G protein coupling specificity. J. Am. Chem. Soc. 136, 11244-11247 (2014).

37. Sandhu, M. et al. Conformational plasticity of the intracellular cavity of GPCR-G-protein complexes leads to G-protein promiscuity and selectivity. Proc. Natl Acad. Sci. USA 116, 11956-11965 (2019).

38. Natochin, M., Muradov, K. G., McEntaffer, R. L. \& Artemyev, N. O. Rhodopsin recognition by mutant $\mathrm{G}(\mathrm{s})$ alpha containing $\mathrm{C}$-terminal residues of transducin. J. Biol. Chem. 275, 2669-2675 (2000)

39. Semack, A., Sandhu, M., Malik, R. U., Vaidehi, N. \& Sivaramakrishnan, S. Structural elements in the Galphas and Galphaq C termini that mediate selective G protein-coupled receptor (GPCR) Signaling. J. Biol. Chem. 291 , 17929-17940 (2016)

40. Yano, A. et al. An aromatic amino acid within intracellular loop 2 of the prostaglandin EP2 receptor is a prerequisite for selective association and activation of Galphas. Biochim Biophys. Acta Mol. Cell Biol. Lipids 1862 , 615-622 (2017)

41. Masson, G. R. et al. Recommendations for performing, interpreting and reporting hydrogen deuterium exchange mass spectrometry (HDX-MS) experiments. Nat. Methods 16, 595-602 (2019).

42. Deutsch, E. W. et al. The ProteomeXchange consortium in 2020: enabling 'big data' approaches in proteomics. Nucleic Acids Res. 48, D1145-D1152 (2020).

43. Perez-Riverol, Y. et al. The PRIDE database and related tools and resources in 2019: improving support for quantification data. Nucleic Acids Res. 47, D442-D450 (2019).

\section{Acknowledgements}

This work was supported by the National Research Foundation of Korea funded by the Korean government (NFR-2018R1A2B6001554 and NRF-2019R1A5A2027340) (K.Y.C.) and funds from Kobilka Institute of Innovative Drug Discovery by the Science and Technology Innovation Committee of Shenzhen (Y.D.). The authors thank Dr. Brian K. Kobilka for valuable discussion. 


\section{Author contributions}

Y.D., J.X., and S.M. purified the $\beta_{2} A R, M 2 R, G i 3$, and GoA proteins. Y.D. and J.X. performed GDP release assay, generated mutant constructs, and wrote the manuscript. H.R.K. prepared GPCR-Gi/o complexes, performed HDX-MS and BODIPY-GTP $\gamma \mathrm{S}$ assays, analyzed mass spectrometry data, and generated mutant constructs. N.M.D. analyzed mass spectrometry data. D.A. prepared Gi3 mutant construct. Y.D. and K.Y.C. initiated the project, supervised research, analyzed data, and wrote the manuscript with contributions from all authors.

\section{Competing interests}

The authors declare no competing interests.

\section{Additional information}

Supplementary information is available for this paper at https://doi.org/10.1038/s41467020-16975-2.

Correspondence and requests for materials should be addressed to Y.D. or K.Y.C.

Peer review information Nature Communications thanks John Burke and the other, anonymous, reviewer(s) for their contribution to the peer review of this work.
Reprints and permission information is available at http://www.nature.com/reprints

Publisher's note Springer Nature remains neutral with regard to jurisdictional claims in published maps and institutional affiliations.

\section{(c) (i)}

Open Access This article is licensed under a Creative Commons Attribution 4.0 International License, which permits use, sharing, adaptation, distribution and reproduction in any medium or format, as long as you give appropriate credit to the original author(s) and the source, provide a link to the Creative Commons license, and indicate if changes were made. The images or other third party material in this article are included in the article's Creative Commons license, unless indicated otherwise in a credit line to the material. If material is not included in the article's Creative Commons license and your intended use is not permitted by statutory regulation or exceeds the permitted use, you will need to obtain permission directly from the copyright holder. To view a copy of this license, visit http://creativecommons.org/ licenses/by/4.0/.

(C) The Author(s) 2020 